Volume 54

Issue 3 Fear, Fraud, and the Future of Financial

Regulation

January 2010

\title{
Short Selling and the News: A Preliminary Report on an Empirical Study
}

Merritt B. Fox

Columbia Law School

Lawrence R. Glosten

Columbia Business School

Paul C. Tetlock

Columbia Business School

Follow this and additional works at: https://digitalcommons.nyls.edu/nyls_law_review

Part of the Antitrust and Trade Regulation Commons, Banking and Finance Law Commons, Law and Economics Commons, Law and Society Commons, Legal History Commons, and the Legal Remedies Commons

\section{Recommended Citation}

Merritt B. Fox, Lawrence R. Glosten \& Paul C. Tetlock, Short Selling and the News: A Preliminary Report on an Empirical Study, 54 N.Y.L. SCH. L. REV. 645 (2009-2010).

This Article is brought to you for free and open access by DigitalCommons@NYLS. It has been accepted for inclusion in NYLS Law Review by an authorized editor of DigitalCommons@NYLS. 


\title{
Short Selling and the News: A Preliminary Report on an Empirical Study
}

\begin{abstract}
ABOUT THE AUTHORS: Merritt B. Fox is the Michael E. Patterson Professor of Law and NASDAQ Professor for the Law and Economics of Capital Markets at Columbia Law School. B.A. (1968), J.D. (1971), and Ph.D. in economics (1980) from Yale University. Lawrence R. Glosten is the S. Sloan Colt Professor of Banking and International Finance at the Columbia Business School and co-director of the Columbia Law School/Business School Program in the Law and Economics of Capital Markets. A.B., Occidental College, 1973; Ph.D. in managerial economics, Northwestern University, 1980. Professor Glosten has been at Columbia since 1989, before which he taught at the Kellogg Graduate School of Management at Northwestern University, and has held visiting appointments at the University of Chicago and the University of Minnesota. Paul C. Tetlock is the Roger F. Murray Associate Professor of Finance at Columbia Business School. Professor Tetlock has been at Columbia since 2008. B.S., Harvey Mudd College, 1999; Ph.D. in economics, Harvard University, 2004. Prior to joining the faculty at Columbia, he was a visiting assistant professor at Yale University, and an assistant professor at the University of Texas at Austin.
\end{abstract}


No subject in securities regulation has generated more heat and less light than short selling. A short sale is the sale of a share that is borrowed from a third party rather than owned by the seller. At a later time, the short seller extinguishes her obligation to this third party by "covering"-purchasing an identical share in the market and then returning it to the third party. If the share price drops, the cost of covering will be less than the proceeds received earlier from the sale and the short seller will make money. Politicians and CEOs rail against short selling as a manipulative tool that artificially pushes share prices below their fundamental values. ${ }^{1}$ Most finance theorists, in contrast, extol short selling's virtues as a practice that helps to quickly incorporate new information into share prices, and thus enhances price accuracy. ${ }^{2}$ Short selling, in their view, also provides valuable liquidity to the market and aids investors in hedging against risk. ${ }^{3}$ Short sales account for $31 \%$ of all sales for NASDAQ listed stocks and $24 \%$ of all New York Stock Exchange ("NYSE") listed stocks. ${ }^{4}$ They are thus an important phenomenon, certainly big enough to affect prices.

Despite the longstanding controversy over this important force in the market, the empirical study of short selling's actual effects, using daily trading data, is in its infancy. By examining the relationship between news and short selling, our project seeks to enlarge the highly incomplete understanding of the causes and effects of short selling and of the impact of attempts to regulate it. Specifically, we seek to determine the so far unexplored relationship between short selling in an issuer's shares and news about the issuer in the time immediately surrounding such transactions. This article is a report on our first very preliminary results from this ongoing project. We find that an increase in the short selling on one day predicts more negative news about the issuer on the day following. Further exploration of our results suggests a number of reasons why this might be so and the regulatory implications that flow from our results.

The first three parts of this article place our inquiry in context. Part I discusses what theory suggests are the potential socially beneficial and socially harmful effects of short selling. The possibility of negative effects has been sufficiently compelling to

1. See, e.g., Frank Ahrens, Report: Rep. Frank Says Uptick Rule Should Be Restored 'Within a Month', Economy Watch, http://voices.washingtonpost.com/economy-watch/2009/03/report_rep_frank_sayz_uptick_r. html (Mar. 10, 2009, 12:57 EST) (Rep. Barney Frank pushed for a quick re-implementation of the uptick rule to avoid market manipulation through short selling.); Ken Sweet, Morgan's Mack: Short Sellers Destroying our Firm, FOXBusiness, Sept. 17, 2008, http://www.foxbusiness.com/story/markets/morgansmack-short-sellers-destroying-firm/ (Morgan Stanley CEO John Mack believed current short sellers are "irresponsible," and are "driving [Morgan Stanley] stock down."); Posting of Shepherd Smith Edwards \& Kantas to Stockbroker Fraud Blog, U.S. Representative Barney Frank Calls on SEC to Widen Investigation of Improper Trading Rumors Surrounding Bear Stearns's Stock, http://www.stockbrokerfraudblog.com/2008/04/ us_representative_barney_frank.html (Apr. 21, 2008) (Rep. Barney Frank is concerned that short-selling in certain banks is being orchestrated to bring stock prices down.).

2. See infra Part I.A.

3. See infra Part I.B.

4. Karl B. Diether, Kuan-Hui Lee \& Ingrid M. Werner, Short-Sale Strategies and Return Predictability, 22 Rev. Fin. Stud. 575, 579 (2009). 
result in varying kinds of regulation over the last seventy-five years, a brief history of which is presented in Part II. Part III provides a survey of the existing empirical literature concerning the causes and effects of short selling and the effects of regulation. This literature, viewed as a whole, is inconclusive as to any negative social effects from short selling and any social gains from its regulation, but there is clearly still much to be learned.

With this background in place, Part IV describes our study of short selling and the news. Part V presents and interprets our results, and Part VI concludes with a discussion of what we have learned to date and how we hope to proceed.

\section{THEORY}

What does theory suggest about the social consequences of short selling's effects on share prices, capital market efficiency, and corporate governance more generally?

\section{A. Socially Beneficial Price Effects}

The free availability of short selling can improve share price accuracy in two ways. First, it can increase the incentives for sophisticated traders to gather and analyze new information relevant to predicting an issuer's future cash flows. Second, short selling can make prices better reflect already-existing information relevant to making such predictions when such information is disparately spread among all the potential traders in the market.

\section{Incentives to Gather and Analyze New Information}

The availability of short selling increases the expected return on the hard work of gathering new publicly available information and analyzing it to help predict an issuer's future cash flows. ${ }^{5}$ These increased incentives arise out of the fact that anyone can be a buyer of an issuer's shares, but, without short selling, only a current holder can be a seller.

There is a fifty-fifty chance that the gathering and analyzing of such information turns out to reveal that an issuer's future cash flow looks better than previously thought. In this event, the person can buy shares of the issuer, whether he currently holds any shares or not, effectively utilizing the results of his hard work to earn an expected profit. He may also benefit from these results by transferring this information and analysis to someone else for a profit. While the well-known imperfections in the market for information means that there are substantial transaction costs involved in obtaining revenues from such a transfer, ${ }^{6}$ any transferee,

5. When we refer to information being "publicly available," we mean anything that is legally observable by a member of the public. Thus, for example, a retail chain store analyst who visits an issuer's stores in order to observe how customers are reacting to a new line of merchandise would be collecting publicly available information.

6. The dilemma faced by the producer of such information is that she wants to maximize her rents and have the information used only as widely as the producer of any valuable input would want it used-i.e., to the point where marginal revenue equals marginal cost. The revelation of the information to another 
whether or not she currently holds any shares of the issuer, can also buy shares and hence earn an expected profit based on the transferred information and analysis. This means that the market for such transfers is broader than if the usefulness of the information were restricted to only those transferees who already owned shares.

There is also a fifty-fifty chance, however, that the hard work will instead turn out to reveal that the issuer's future cash flows look worse than previously thought. In this event, without short selling, the person who did the hard work can only sell shares of the issuer if he currently holds such shares, thereby limiting his sales to the number of shares that he holds. Thus, he will either be entirely unable, or limited in his ability, to directly use the results of his hard work to earn an expected profit. Moreover, it is harder to profit by transferring these results to someone else than when the prediction turns out to be better than previously thought. The transaction costs of making a transfer are enlarged by the fact that the person who did the hard work has to identify, from among all market participants, only those who currently hold shares of the issuer. And he must do so without making the results public to the world at large, thereby destroying their trading value. Thus, without short selling, the rewards for the individual's hard work if the results turn out to be negative are less than the rewards if the results turn out to be positive.

In contrast, if short selling is freely available, just as anyone can be a buyer, anyone can be a seller. If the results generated by the hard work turn out to be negative, the rewards for this work are therefore no longer handicapped. If the results turn out to be positive, the rewards for this work are just as large as if short selling is prohibited. Since the availability of short selling increases the likelihood of profiting if one of the outcomes of hard work materializes-negative results-without decreasing the likelihood of profiting if the other outcome materializes-positive results-short selling increases the overall expected return on performing such work.

An increase in the expected return on such hard work will increase the amount that will be done, resulting in more accurate predictions of future cash flows, which will in turn result in more accurate share prices as such information becomes the basis of trades. More accurate share prices enhance efficiency in the economy by improving corporate decision making related to the selection of new investment projects as well as to the operation of already-existing projects. ${ }^{7}$

A possible illustration of the importance of short selling in providing incentives for gathering and analyzing information is the reported unhappiness of hedge funds

undermines her monopoly position because, absent an agreement between the producer and the transferee, anyone who receives it can then "produce" additional units of it at very low marginal cost. Agreements between the original producer and another to limit the use and further transfer of the information are difficult to draft and enforce and thus entail significant transaction costs. Transfers are further burdened by the fact that it is hard for the potential transferee to evaluate information without learning it, at which point there is no need to pay for it. Kenneth J. Arrow, Economic Welfare and the Allocation of Resources for Invention, in The Rate and Direction of Inventive Activity 609, 616 (Richard R. Nelson, ed. UMI) (1962).

7. For a more extended discussion of this point and a review of the relevant literature, see Merritt B. Fox et al., Law, Share Price Accuracy, and Economic Performance: The New Evidence, 102 Mich. L. Rev. 331, 337-41 (2003). 
during the summer and fall of 2008 when temporary restrictions were placed on the short selling of certain financial firms. ${ }^{8}$ While these complaints were probably viewed by many as an inappropriate desire to further profit from the misery in the financial sector, ${ }^{9}$ the actual picture was more complicated. The efficient market hypothesis suggests that even in a crisis such as the one experienced in 2008 , there is no more reason to believe that at any given moment in time financial institution share prices will continue to decrease rather than increase. ${ }^{10}$ Which direction these prices will go depends on new information as it becomes available, and new information is, by definition, unpredictable in its implications. Hedge funds and the individuals working for them had invested heavily in the capacity, as new information became available, to make better predictions concerning the future cash flows of these issuers than the predictions made by others in the market. ${ }^{11}$ To the extent that the new regulations prevented them from engaging in short selling, they were more restricted in their ability to earn a return on these investments when their analysis of new information turned out to suggest lower future cash flows than what was suggested by previously available information. ${ }^{12}$

8. See, e.g., The Brief: Institute for Law and Economics, William Ackman Says a Ban on Short Selling is Shortsighted, Penn Law J. Online, Spring 2009, http://www.law.upenn.edu/alumni/alumnijournal/ Spring2009/the_brief/page10.html (Ackman believed that the September 2008 ban on short selling is misguided and "strait-jacket[s]" hedge fund managers.); James Mackintosh et al., Ban on Shorting Banks Failed Badly, Say Experts, FinancialTimes.com, Mar. 11, 2009, http://www.ft.com/cms/s/0/34c7e12a0ddd-11de-8ea3-0000779fd2ac.html?nclick_check=1 (Hedge funds and academics believe that the short selling restrictions did not work and short selling funds are being "demonized."). For a discussion of these restrictions, see infra Part III.B.3.

9. See, e.g., Sara Hansard, Hedge Funds Alone in Fight Against Short-selling Curb, Invest ment News, Aug. 11, 2008, http://www.investmentnews.com/article/20080811/REG/827522981.

10. Financial economists describe a market displaying "semi-strong" efficiency as one where "prices will adjust immediately to public information” after which security returns are unpredictable. RICHARD A. Brealey, Stewart C. Myers \& Franklin Allen, Principles of Corporate Finance 359 (9th ed. 2008). In such a market, no ordinary investor, on an expected basis, can beat the market by collecting and acting on public information because it is already reflected in price. $I d$.

11. See, e.g., James Chanos, President, Kynikos Associates, Prepared Statement for the U.S. Securities and Exchange Commission Roundtable on Hedge Funds, Panel Discussion: "Hedge Fund Strategies and Market Participation," (May 15, 2003), available at http://www.sec.gov/spotlight/hedgefunds/hedgechanos.htm; An 'abomination'? Critics attack SEC's short-selling ban, L.A. Times, Money \& Company Blog, http://latimesblogs.latimes.com/money_co/2008/09/some-reaction-t.html (Sept. 19, 2008, 13:07 PST) (negative reactions of both hedge funds and academics to the ban on short selling); Posting of John Hempton, In Defence of Naked Short Selling-Or Why the Crackdown on a Phoney Problem is Costing Taxpayers at Least a Billion Dollars, Bronte Capital Blog, http://brontecapital.blogspot.com/2009/06/ in-defence-of-naked-short-selling-or.html (June 16, 2009, 23:55 AEST) (arguing that the ban on short-selling makes the market less efficient and costs taxpayers money). A less benign explanation of the hedge fund unhappiness at the short sale restrictions is that during a financial crisis, short selling the shares of financial firms might be profitable because the decline in share price resulting from the short sale trade could damage the underlying business of the firm and hence lead to a decline in fundamental value that would be reflected in price longer term. See infra Part I.C.3.

12. Another illustration of the importance of short selling for incentives is the existence of hedge funds that specialize in looking for hints that an issuer's accounting is incorrect and is exaggerating earnings. Such funds would be unlikely to exist if short selling were not available because their whole business model is 


\section{Better Reflection of Disparately Spread Information}

Short selling can also help improve price accuracy by helping prices better reflect the implications of information that market participants have already gathered and analyzed. Such information is likely to be disparately spread over the range of market participants, with some participants possessing some bits of such information and other participants possessing other bits. ${ }^{13}$ Without short selling, an issuer's share price reflects more fully, or at least more precisely, the views of investors whose information sets yield an optimistic assessment of the issuer's future cash flows than it reflects views of investors whose information sets yield pessimistic assessments. ${ }^{14}$ This, again, is due to the fact that while all members of the investment community whose information results in an optimistic view can be buyers, for members whose information yields a pessimistic view, only those who happen to already hold an issuer's stock can be sellers. The exact way that the lack of short selling undermines price accuracy, however, depends on one's assumptions about investor behavior. An assumption that all investors are fully rational yields one conclusion. The contrasting assumption that a substantial percentage of investors are "noise traders" who irrationally follow fads, fashions, and trends, yields a different conclusion.

a. Rational-investor model. If one assumes that all investors are fully rational, an absence of short selling, combined with the fact that the distribution of information among investors makes some investors more optimistic than others, will not bias share prices to be on average too high. Participants in the market will know about the unavailability of short selling and its implications in terms of the level of trading activity by investors with different views. Therefore, the market will consistently discount prices to compensate for what would otherwise be an upward bias. ${ }^{15}$

Even under this rational-investor model, however, share prices will be less accurate without short selling. Imagine that the information sets of those investors who have pessimistic views about certain issuers make such investors only mildly pessimistic about the issuers' prospects. In contrast, the information sets of those investors who have pessimistic views about the rest of the issuers in the market make

to look for bad news and to try to profit by selling when they find it. For example, Kynikos Associates is described as a "private investment management company . . . . [which] specializes in short selling . . . [and] profits in finding fundamentally overvalued securities." Chanos, supra note 11.

13. In this informal model that treats information as bits, one can imagine that the bits that are relevant to a given trader predicting an issuer's future cash flows would include not only the bits relating to the issuer itself and the input and output markets in which the issuer operates, but also the bits that inform the trader's particular approach to doing analysis. Thus, two persons might have the same set of the first type of bits, but come to different predictions concerning the issuer's future cash flows, because of differences in their sets of the second type of bits. This is a way that one person could be an "optimist," who thinks that the stock is priced below its fundamental value, and another a "pessimist," who thinks it is priced above.

14. For models working out this proposition, see, e.g., Douglas W. Diamond \& Robert E. Verrecchia, Constraints on Short-Selling and Asset Price Adjustment to Private Information, 18 J. Fin. Econ. 277 (1987); Edward M. Miller, Risk, Uncertainty, and the Divergence of Opinion, 32 J. FIn. 1151 (1977).

15. Diamond \& Verrecchia, supra note 14 , at 278. 
such investors severely pessimistic about these other issuers' prospects. When there is no short selling, the discount imposed on all issuers is an average of the views of the mild and the severe pessimists. This is because the market cannot distinguish into which of the two groups any given issuer falls; rather the market only knows that the pessimist investors' views concerning the issuer, whether as a group they are mild or severe pessimists, are underrepresented in trading.

If short selling were available, the views of pessimists would instead be fully represented in trading. The issuers whose pessimists are only mildly pessimistic would have their shares priced higher than the prices that would have resulted from the general discount imposed on all issuers in the absence of short selling. Similarly, the issuers whose pessimists are severely pessimistic would be priced lower than what would have resulted from this general discount. Thus, under the rational-investor model, the free availability of short selling would lead to prices that more fully and accurately reflect the stock of information in the world concerning an issuer's prospects. Prices would differentiate between an issuer where a fraction of investors possess mildly negative information about the issuer, from an issuer where a fraction of investors possess severely negative information about the issuer.

b. Noise-trader model. Now, instead of full rationality, assume that many investors are "noise traders" who irrationally follow fads, fashions, and trends. ${ }^{16}$ With this assumption, different implications arise from the fact that without short selling, investors whose information sets give them a pessimistic assessment of an issuer's future cash flows are not as fully represented in trading as investors whose information sets give them an optimistic assessment. Unlike the rational-investor model, knowledge by some traders of this difference in trading representation will not necessarily lead to share prices being adequately discounted in the market. The noise traders, who do not consider these trading representation differences in their decisions, are sufficiently numerous that their influence on prices is not totally counterbalanced by "smart money" arbitragers, who do consider this fact. ${ }^{17}$ As a result, share prices may be biased upward for sustained periods of time. If a bubble begins to form with respect to an issuer, persons who trade on the basis of a rational evaluation of future cash flows will all be pessimists. ${ }^{18}$ After these investors sell whatever shares they hold of the issuer, they no longer have any influence on its share price.

Short selling is not necessarily a complete cure to the problems caused by noise traders, but if short selling were freely available, the imbalance in how much the optimists and the pessimists are represented in trading would cease, and bubbles would in turn be more likely to burst before growing too large. ${ }^{19}$ Under the noise-

16. See, e.g., Andrei Shleifer \& Lawrence H. Summers, The Noise Trader Approach to Finance, J. Econ. Persp., Spring 1990, at 19, 19-20.

17. See J. Bradford De Long et al., Noise Trader Risk in Financial Markets, 98 J. Pol. Econ. 703 (1990).

18. See Jose A. Schienkman \& Wei Xiong, Overconfidence and Speculative Bubbles, 111 J. Pol. Econ. 1183, 1185-86 (2003).

19. See Christopher L. Culp \& J.B. Heaton, Naked Shorting (Apr. 26, 2007), available at http://papers.ssrn. com/sol3/papers.cfm?abstract_id=982898; Miller, supra note 14, at 1160-61; Eli Ofek \& Matthew 
trader model, freely available short selling thus enhances share price accuracy because bursting bubbles before they become large keeps prices closer on average to their fundamental values.

\section{B. Other Socially Beneficial Effects}

The availability of short selling also greatly facilitates the ability of a dealer to provide market-making services. This is because the only alternative way for a dealer to provide liquidity in front of heavy selling is to hold a huge inventory, which is very expensive. ${ }^{20}$ As a result of this concern, dealers are usually exempted from any short selling restrictions imposed on other traders in the market. Designated dealers have become far less important, however, as other traders now provide much of the liquidity in the market through the placement of limit orders. The ability of these other traders to provide liquidity would be similarly hindered if they were unable to short sell. Thus, unlike the early days of NASDAQ ${ }^{21}$ the ability of all traders, not just dealers, to short sell freely enhances the amount of liquidity in the market. ${ }^{22}$

\section{Socially Harmful Price Effects}

The concerns that short selling results in social harms have tended not to be as precisely articulated as the claims of short selling's socially beneficial effects. This is most likely due to the fact that negative concerns are more often expressed by politicians and corporate executives engaged in ordinary public discourse, rather than by financial economists in the more rigorous language of professional academia. Behind some of the seemingly exaggerated rhetoric of short selling's critics, however, a number of coherent stories can be told-some potentially more serious than others-about situations where the availability of short selling might have socially harmful effects.

\section{Pure Manipulation-Depressing Price and Repurchasing}

One story of how the availability of short selling can have socially harmful effects involves the use of short selling to profit from manipulation. Under this scenario, the manipulator does not believe the stock to be overpriced. She nevertheless sells short

Richardson, DotCom Mania: The Rise and Fall of Internet Stock Prices, 58 J. Fin. 1113, 1113 (2003).

20. See generally Thomas E. Copeland \& Dan Galai, Information Effects and the Bid-Ask Spread, 38 J. Fin. 1457 (1983); Lawrence R. Glosten \& Paul Milgrom, Bid, Ask and Transaction Prices in a Specialist Market with Heterogeneously Informed Traders, 14 J. Fin. Econ. 71 (1985); Sanford J. Grossman \& Merton H. Miller, Liquidity and Market Structure, 43 J. Fin. 617 (1988); Hans R. Stoll, The Supply of Dealer Services in Securities Markets, 33 J. Fin. 1133 (1978).

21. NASDAQ stands for the National Association of Securities and Dealers Automated Quotation. NASDAQ, Frequently Asked Questions, http:www.nasdaq.com/help/helpfaq.stm (last visited Feb. 23, 2010).

22. This negative influence has been demonstrated in the case of financial firms. See Ekkehart Boehmer, Charles M. Jones \& Xiaoyan Zhang, Shackling Short Sellers: The 2008 Shorting Ban (Johnson School Research Paper Series No. 34-09, 2009), available at http://ssrn.com/abstract=1412844. 
a substantial block of its shares, perhaps in a series of transactions, knowing that these sales in the aggregate will push down the price of the shares. At a subsequent time, she will need to repurchase the same number of shares in order to cover. If, because the price has been pushed down, she can repurchase these shares at prices that on average are less than what she sold them short for, she can profit. ${ }^{23}$

Such a manipulation, when successful, has two socially harmful effects. First, on average, it moves share prices, at least temporarily, away from their fundamental values because the decrease in price is unrelated to any change in information about the future cash flows of the issuer involved. Second, it transfers wealth to the class of traders who are capable of such transactions from the substantial majority of investors who are not, lowering the second group's expected return from investing and thereby reducing their incentives for investing in the market at all. It should be noted, however, that under most circumstances, such pure manipulations cannot be expected to yield much profit, if any, because the purchase orders needed to effect a cover will push prices up just as the sale orders prompted by the original short sale pushed them down. ${ }^{24}$

\section{Depressing Price in Order to Profit on a Third-Party Contract}

A wide variety of contracts have terms that provide one of the parties with a payoff that depends on the market price of an issuer's shares at a particular point in time. For the other party to such a contract, the lower the issuer's price, the less it must pay out under the contract. The party that benefits under the contract from the lower price ("low-price beneficiary") has an incentive to push down the market price of the issuer's shares at the point in time specified in the contract for determining the

23. This is the alleged tactic employed by participants in the "bear raids" of the early 1930s that so much disturbed the drafters of the Securities Exchange Act of 1934. 7 Louis Loss \& Joel Seligman, Securities Regulation 3200 n.213 (3d ed. 2003).

24. The profitability of a pure manipulation trade initiated with a short sale requires that the price response to a sell be greater than the price response to a buy, and that this reduced response to a buy will persist long enough to accomplish putting on the short position and then covering that position. To understand the profit arithmetic of the manipulative trade, suppose that on the bid side of the book, the schedule of limit orders is approximated by the linear relation $\mathrm{P}-\mathrm{b}_{0}-\mathrm{b}_{1} \mathrm{Q}$. That is, this expression describes the last (or marginal) price for a sell (short) of $Q$ shares. This implies that the average price is $\mathrm{P}-\mathrm{b}_{0}-\mathrm{b}_{1} \mathrm{Q} / 2$. Furthermore, the new spread midpoint moves to $\mathrm{P}-\mathrm{b}_{1} \mathrm{Q}$ as the limit order book responds to the information that they believe is in the trade. Lawrence R. Glosten, Is the Electronic Open Limit Order Book Inevitable? 49 J. Fin. 1127 (1994). Suppose the limit orders on the ask side of the book, after the short position is put on is described by $\left(P-b_{1} Q\right)+a_{0}+a_{1} Q$, and $a_{1}<b_{1}$. Then, the profit per share from a manipulative trade of $\mathrm{Q}$ shares is $-\left(\mathrm{b}_{0}+\mathrm{a}_{0}\right)+\left(\mathrm{b}_{1}-\mathrm{a}_{1}\right) \mathrm{Q} / 2$. For a moderately liquid stock, with a price level of 30 , the small trade spread component $\left(b_{0}+a_{0}\right)$ will be on the order of .03 per share. A reasonable estimate of $b_{1}$ might be on the order of $\$ .10$ per share per 100,000 shares. Suppose that $a_{1}$ is $\$ .06$. Then the profit per share for a one million share manipulation is on the order of $-.03+.04 * 10 / 2$ or $\$ .17$ per share. This is a total profit of $\$ 170,000$ on capital of $\$ 30,000,000$, for a return of 56 basis points. This return is over a very short interval of time, but there is probably no expectation that this situation will exist on a regular basis. Indeed, sophisticated players in the market may recognize this situation and withdraw liquidity from the offer side of the book. Furthermore, this manipulation will only work if there are, in fact, no informed buyers in the market waiting to take advantage of the manipulator's manipulation. The conclusion from these calculations is that some manipulations may be profitable, but they may not be a consistent source of profit. 
payoff. Just in advance of this point in time, the low-price beneficiary, without any belief that the shares are priced above their fundamental value, pushes the price down by selling short a substantial block of stock. When she later covers, she may end up repurchasing at prices that are on average as great as, or even greater than, the prices at which she sold short. She nevertheless may, on a net basis, profit handsomely as a result of the gains she experienced from having reduced her payout under the contract.

One harmful social consequence of such behavior is that, like the use of short selling for pure manipulation, it moves share prices away from their fundamental values. But this harm too is likely to be limited. The deviation would likely last only a very brief period of time, because the contract beneficiary would want to cover as quickly as possible in order to minimize risk. The social harm from such a brief deviation in price would normally not be great because the mechanisms that depend on price accuracy to enhance efficiency in the real economy are not sufficiently fast acting to be seriously affected.

A second harmful consequence of such behavior is the expenditure of social resources by the other party to the contract to defend against the possibility that she is disadvantaged under the contract by the low-price beneficiary short selling just in advance of the time specified for the payoff. One way the other party may be able to defend herself is to insist at the time of contracting on more complicated contractual terms that would prevent being disadvantaged by such short selling. More complicated contractual terms in turn require the parties to devote more time and effort to negotiation and drafting. ${ }^{25} \mathrm{~A}$ third, related problem is that such defenses may be ineffective or too costly to be worthwhile and a useful kind of contractual term is simply not used as frequently as would be desirable because of its potential to be undermined by short selling.

These problems, though real, are again probably not serious enough to justify general regulation against short selling, even if short selling had no beneficial effects. The resources consumed and inefficiencies created as a result of these problems are probably not very great relative to the enforcement costs of any kind of regime that effectively would prevent short selling.

\section{Diminishing the Underlying Value of the Firm}

According to the analysis above, it is difficult, on an expected basis, to buy back for a profit shares that have been sold short. Thus, attempts at pure manipulation are not on average likely to make much money, if any. But this analysis assumes that the underlying value of the firm is unchanged by the initial drop in price caused by the short seller's sell orders. This is a reasonable assumption for most firms-the operations

25. The terms, for example, might include some kind of verifiable prohibition against short selling by the low-price beneficiary around the time of the trigger point. Another defense would be for the other party to make her own intervention in the market-purchasing shares just in advance of the time specified for determination of the payoff in order to counter the price-diminishing impact of any short sales by the low-price beneficiary. 
of their underlying businesses, and hence the cash flows generated by their operations, are largely unaffected by short-term changes in the price of their shares.

However, the operations of some kinds of firms, especially at certain times, may be significantly affected by such short-term share price changes. A financial firm during a time of a financial crisis is the most likely example. Such a firm's ability to perform its day-to-day underlying businesses-lending, trading, and underwritingdepends on its ability to maintain its capital base. As we have seen recently, this base can erode rapidly in a financial crisis and the lost capital can only be replaced with new sales of equity. When there has been such erosion in an issuer's capital base, if the price of its equity is temporarily depressed, the financial firm either has to forego business or dilute equity. Thus, its future cash flows per share, and hence its fundamental value, can be reduced by a temporary drop in share price. ${ }^{26}$

Consider a trader during a crisis who thinks that the decline that has already occurred in the share price of a given financial firm is sufficient to reflect the new realities brought on by the crisis and so she does not believe that these shares are overpriced. The trader nevertheless sells short a substantial block of the firm's shares. The initial share-price drop caused by her short sale may become a self-confirming hypothesis in the sense that the share-price drop may lead to a drop in the share's fundamental value because of the damage of the lower share price to the firm's underlying business. Moreover, because of this self-confirming aspect, short selling the issuer's shares could easily become contagious. Short sales in such a situation could be profitable on an expected basis because, reflecting the decline in fundamental value caused by the contagious short-selling-induced share-price drop, the price at which the short sellers cover would be lower on average than the short sale price. Fear that this sort of phenomenon was underway at points during the summer and fall of 2008 appears to underlie the thinking that led to the imposition of greater restrictions on short selling of shares in U.S. financial firms during this period. ${ }^{27}$ Even a financial firm is not seriously vulnerable to this kind of problem most of the time, however. Absent a financial crisis eroding its capital basis, it too can, without

26. This is very different from a manufacturing firm, which, if it suffers a temporary decline in share price unrelated to its fundamentals can, without great damage to its future cash flows per share, either temporarily defer real investments or raise funds for the real investment in ways other than equity sales.

27. See infra Part II.B.3. On September 18, 2008 the SEC instituted a temporary emergency ban on the shorting of 799 financial services companies because of "[concern] about recent sudden declines in the prices of a wide range of securities ... [which] can give rise to questions about the underlying financial condition of an issuer, which in turn can create a crisis of confidence without a fundamental underlying basis.” Emergency Order Taking Temporary Action to Respond to Market Developments, Exchange Act Release No. 34-58592, 73 Fed. Reg. 55,169 (Sept. 18, 2008). The following day, the SEC reiterated its belief that "unbridled short selling is contributing to the recent, sudden price declines in the securities of financial institutions unrelated to true price valuation. Financial institutions are particularly vulnerable to this crisis of confidence and panic selling," and further stated that in addition to the new shorting ban and the previous emergency orders increasing short sale reporting and easing restrictions on issuer repurchase, it "may consider additional steps as necessary to protect the integrity and quality of the securities markets and strengthen investor confidence." Press Release, U.S. Sec. \& Exch. Comm'n, SEC Halts Short Selling of Financial Stocks to Protect Investors and Markets, SEC Release 2008-211 (Sept. 19, 2008), http://www.sec.gov/news/press/2008/2008-211.htm. 
much damage, wait out a temporary dip in share price before selling new equity. Thus, this kind of social harm from short selling, if it occurs at all, is probably an exceptional event and at most would only call for temporary restrictions on short selling that are limited to the shares of firms in a single sector.

\section{Short Selling Combined with the Creation of False News}

Two potentially profitable strategies can be based on combining short selling with the spreading of false news. One would be to short sell first, next spread false negative news that depresses prices, and finally cover at the depressed price. The other is to first spread false positive news that increases share price, next short sell at the inflated price, and finally cover after the market realizes the falsity of the news and the price inflation has dissipated. Both strategies are prohibited by SEC Rule 10b-5, promulgated under section 10(b) of the Securities Exchange Act of 1934 ("Exchange Act"). ${ }^{28}$

This more general fraudulent practice of spreading false news and trading to take advantage of the resulting distortion in price, in whatever form undertaken, has a number of harmful social effects. Two of these resemble the harmful effects of a successful pure manipulation. Like a pure manipulation, the spreading of false news motivated by the prospect of profiting from the distortion in price will move share prices temporarily away from their fundamental values and thus reduce, at least a bit, the overall level of share price accuracy and the benefits that accurate prices yield for the efficient operation of the real economy. Also, like a successful pure manipulation, the fraudulent practice of spreading false news and trading to take advantage of the resulting distortion in price transfers wealth away from the substantial majority of investors to the class of traders who are capable of implementing the fraud. This lowers the first group's expected return from investing and reduces their incentives for investing in the market at all.

This more general fraudulent practice of trading on the distortion created by false news can lead to additional social harms as well. First, because the trader spreading the false news knows the news is false and the other party to the transaction does not, the fraud results in an information asymmetry between the trader and other parties to his trade. The prospect of possibly entering unknowingly into a trade with a trader undertaking such a fraud will lead market makers to increase their bid/ ask spreads. ${ }^{29}$ An increased bid/ask spread in turn reduces liquidity, which results in

28. Deliberately spreading false news and trading to take advantage of the resulting distortion in price violates the Rule 10b-5 prohibition against the making of "any untrue statement of a material fact . . . in connection with the purchase or sale of a security.” 17 C.F.R. $\$ 240.10 b-5$ (2009). Recently, the SEC has reaffirmed its commitment to "vigorously investigate and prosecute those who manipulate markets with this witch's brew of damaging rumors and short sales." Michael J. de la Merced, S.E.C. Accuses Trader of Spreading Rumors, N.Y. Times, Apr. 25, 2008, at C6. This has led to charges such as those filed in the SDNY against trader Paul S. Berliner for shorting in connection with rumor-mongering. Complaint, SEC v. Paul S. Berliner, No. 08-CV-3859 (S.D.N.Y. Apr. 24, 2008) available at http:// www.sec.gov/litigation/complaints/2008/comp20537.pdf (case settled in Administration Proceeding File No. 3-13035).

29. Glosten \& Milgrom, supra note 20; see also Larry Harris, Trading \& Exchanges: Market Microstructure For Practitioners 289-91, 299-302 (Oxford Univ. Press 2003). 
parties inefficiently foregoing secondary market trades that they would otherwise find worthwhile to undertake. The increased bid/ask spread also makes engaging in trading based on the gathering and analyzing of fundamental information more expensive and, by reducing the profitability of such trading, reduces the level of such information gathering and analysis and hence share price accuracy. ${ }^{30}$ Also, the more false news that is spread, the more real resources investors will expend in the effort to detect whether any particular piece of news is true or false (i.e., the greater the precaution costs).

The fraudulent practice of spreading false news and trading to take advantage of the resulting distortion is therefore clearly socially harmful. The relevant question for this study, however, is whether the availability of short selling significantly increases the level of this harmful practice. Arguably it will not, because there are alternative ways of profiting from spreading both negative and positive news without the use of short sales. The alternative strategy for profiting from spreading false negative news is to spread the news first, next purchase the shares at the resulting depressed price, and then resell the shares after the market realizes the falsity of the news and the depression in price dissipates. Another alternative strategy for profiting from spreading false positive news is to purchase the shares before spreading the news and then sell immediately after the news has been spread at the resulting inflated price.

A more sophisticated approach to the question, though, suggests that this argument is flawed and that the availability of short selling does increase the level of the fraudulent practice of spreading false news and trading to take advantage of the distortion in price. Understanding this more sophisticated approach starts with two observations. The first observation is that for some kinds of information, at least some of the time, convincingly spreading false negative information may be easier than convincingly spreading false positive information, and that for some other kinds of information the opposite may be the case.

For example, positive false news is sometimes easier to spread because it is probably less likely to be immediately corrected by the company. During rising times, false positive news may also be more believable because people want to believe it and it is consistent with the overall mood of euphoria. On the other hand, where avoiding specificity is desirable, false negative information, because of the power of innuendo, is probably easier to spread than false positive information. ${ }^{31}$

30. This is the same negative effect as is caused by trading on the basis of confidential information from inside the firm. See Michael J. Fishman \& Kathleen M. Hagerty, Insider Trading and the Efficiency of Stock Prices, 23 Rand J. Econ. 106, 110 (1992); Zohar Goshen \& Gideon Parchomovsky, On Insider Trading, Markets, and "Negative" Property Rights in Information, 87 VA. L. Rev. 1229, 1238-43 (2001).

31. At the start of the financial crisis in the summer of 2008, the SEC, for example, appeared more concerned with the ease with which false negative rumors were spread than false positive ones. It justified the emergency imposition of new rules relating to the borrowing and delivery requirements on short sales of financial institution shares, in part, on concern that negative false rumors concerning them had fueled share price decline below the level that would have resulted from the normal price discovery process. Emergency Order Taking Temporary Action to Respond to Market Developments, Exchange Act Release No. 58,166, 73 Fed. Reg. 42,379, paras. 1-2 (July 15, 2008). 
The second observation is that the legal and financial risks associated with the fraud of spreading false news and trading to take advantage of the resulting distortion in price may, under some circumstances, be less when the initial trade is made in advance of spreading false information and the second transaction is made immediately after the false news has had its full impact on price. ${ }^{32}$ And, under other circumstances, the fraud may be harder to detect or less risky financially when the initial trade is made after the false information has been spread but is still distorting the price, and the reverse trade is made after the market realizes the truth and the price distortion dissipates. ${ }^{33}$

32. The legal risk associated with a trader engaging in this fraudulent practice is the risk of detection and hence of a legally imposed sanction. The financial risk is the variability in the possible return from engaging in this fraudulent practice and the effect of this variability on the overall level of riskiness of the trader's portfolio. Engaging in the practice un-diversifies the trader's portfolio, which in turn makes the riskiness of the trader's portfolio sensitive to the variability in the return from engaging in the fraudulent practice even though this variability represents idiosyncratic risk.

33. As for legal risk, on the one hand, engaging in the initial trade after, rather than before, spreading false news may be harder to detect because significant news tends to increase the overall volume of trading. Paul C. Tetlock, Giving Content to Investor Sentiment: The Role of Media in the Stock Market 62 J. Fin. 1139 (2007). On the other hand, where the false news to be spread is positive, detection of the fraud may be more difficult if the initial trade is before the spreading of the news because it avoids needing to engage in a short sale to profit. Short sales are more conspicuous because they represent a smaller percentage of trades.

As for financial risk, where the initial trade occurs first and the spreading of the false news occurs thereafter, the primary source of the variability in the possible return from engaging in the fraud stems from the inability of the trader, at the time she engages in the initial transaction, to predict precisely the extent, if any, to which the false news will affect price. The second source of variability is all the other factors that will push the issuer's price around during the period between the first transaction and the second transaction. The importance of this source of risk is limited by the fact that the time between the fraud's first and second transaction is likely to be short, probably no more than a day or two. This is because the trader will presumably spread the false news as soon as the initial transaction is completed. For a stock trading in a market that is efficient with respect to public announcements of the issuer, even news that is publicly disseminated by a non-issuer source, for example a news service or an analyst, and that has as its ultimate source a publicly unnamed person (the trader spreading the false news), is likely to have its full impact on price very quickly. Once the false news has had its full impact on price, the trader will immediately want to engage in the second transaction in order to eliminate any further risk and lock in her profits.

Where the spreading of the false news occurs first and the initial trade occurs thereafter the relative importance of these two sources' financial risk are reversed. The primary source of this variability in the possible return stems from all the other factors that will push the issuer's price around during the period between the fraudulent first transaction and the second transaction. This is because there may well be an extended period of time before the market totally realizes the falsity of the news and the impact of this news on price dissipates. Since the trader cannot make her full return from engaging in the practice until the impact on price completely dissipates, the trader remains undiversified for a considerable period of time and cannot lock in her profits. The other source of variability-the inability of the trader, at the time she engages in the initial transaction, to ascertain precisely the extent that the false news has affected prices-is now the less important source of risk. Compared to the scenario where the initial transaction precedes the spreading of the false news, the trader in this scenario has the advantage of being able to observe the price change before she commits by engaging in the first transaction. Because other factors may affect price at the same time as the false news is being spread, it may not be possible to ascertain perfectly the impact of the false news on price. Still, for assessing this impact, being able to observe the price change is a big advantage over not being able to observe it. 
These two observations suggest a variety of possible combinations of the relevant factors. For situations representing many of these combinations, the more advantageous way of undertaking the fraud involves the use of a short sale. In at least some of these situations, if short selling were not available, the fraud would no longer be attractive enough to be worthwhile. Thus, the availability of short selling would increase the prevalence of fraud involving the spreading of false news and its associated social harms. Indeed, compared to the three other kinds of practices involving short selling discussed here-pure manipulation, depressing price to profit from a contract with a third party, and profiting from the diminished underlying value that results from the short sales' initial depression of prices-theory would suggest that using short selling to profit from spreading false news may have the most consistent potential for having significant harmful social effects, though it is possible to argue otherwise. Thus, such activity definitely seems worthy of empirical investigation.

\section{Short Selling on the Basis of Negative Inside Information and Its Effects}

One other practice-trading on the basis of negative inside information-will also likely be more prevalent if short selling is available because ownership of an issuer's shares will not be necessary to take advantage of any such information that a trader might come to possess. The trader can simply sell short and then cover when the price declines after the information becomes public. Trading on the basis of negative inside information has three of the same socially harmful effects as spreading false news and trading to take advantage of the resulting distortion in price: (i) transferring wealth to those able to engage in the practice, thereby discouraging participation in the market by those who cannot; (ii) raising the bid/ask spread with the accompanying efficiency-reducing decrease in market liquidity and share-priceaccuracy-inducing trading based on fundamental analysis; and (iii) adding to the level of real resources devoted to precaution costs. However, unlike spreading false news, which has no redeeming virtues, trading on negative inside information, though illegal under many circumstances, has countervailing social benefits because, at the time it is undertaken, it moves an issuer's share price toward-rather than away from-its fundamental value. As a result, the increase in this practice that results from the availability of short selling, depending in part on its prevalence relative to the practice of spreading false news combined with trading, may on balance have less negative social consequences.

\section{HISTORY OF REGULATION}

Since the onset of the Great Depression, the perception that short selling can be socially harmful has led to a variety of kinds of regulation. ${ }^{34}$

34. More detailed histories of U.S. short selling regulation can be found at Charles M. Jones, Shorting Restrictions: Revisiting the 1930s, October 2008, http://www.gsb.columbia.edu/whoswho/getpub. cfm?pub=3233; Amendments to Regulation SHO, SEC Release No. 34-59748, 17 C.F.R. pt. 242, at 11-17 (Apr. 10, 2009). 


\section{A. The Depression and Establishment of a Regulatory Structure}

In September 1931, the NYSE briefly banned short selling altogether. ${ }^{35}$ Soon after the lapse of this ban, the NYSE began to prohibit short sales at a price below the price of the immediately preceding last sale and to regulate the lending of shares. ${ }^{36}$ Also, while financial theorists today are skeptical that pure manipulations can be expected to yield significant profits, the legislative hearings and investigations leading up to the passage of the Securities Act of 1933 ("Securities Act") and the Exchange Act led many persons to believe that a substantial cause of the enormous drop in share prices beginning in the latter part of 1929 was the practice of bear raids - a group of traders selling short a large amount of an issuer's securities with the hope that they can profit by covering through repurchases at the depressed price resulting from their sell orders. ${ }^{37}$ As a result, when the Exchange Act was passed in 1934, it included section 10(a), which prohibits short sales in violation of any rule promulgated by the SEC in furtherance of the public interest or for the protection of investors. ${ }^{38}$

The SEC did not utilize its authority under section 10(a) immediately. But shortly after the market break of 1937, when officials believed concentrated short selling to have occurred, the SEC adopted Rule 10a-1, which imposed, subject to certain exceptions, the "uptick" test on short sales of exchange-listed securities. This test allowed short sales only if they were either at a price above the price of the last reported sale, or at a price equal to the last reported sale (where the last reported sale was above the price of the reported sale immediately preceding it)..$^{39}$ Eventually, with a several-decade delay, the more heavily traded NASDAQ securities were also subject to similar regulations, but with a test based on the most recent best bids rather than reported sale prices. ${ }^{40}$

35. Amendments to Regulation $\mathrm{SHO}$, supra note 34 , at 1 .

36. See id; see also U.S. Sec. \& Exch. Comm'n, Report of the Special Study of the Securities Markets of the Securities and Exchange Commission, reprinted in H.R. Doc. No. 88-95 Part 2, at 251 (1963) (sixteen exchanges adopted this rule in 1935).

37. See Loss \& Seligman, supra note 23, at 3200 n.213.

38. Securities Exchange Act of 1934 § 10(a), 15 U.S.C. § 78j (2006).

39. Jones, supra note 34, at 20; see also Exchange Act Release No. 1548, 1938 WL 32911 (Jan. 24, 1938).

40. Originally adopted in 1994, NASD Rule 3550 (renumbered as Rule 5100 by SR-NASD-2005-087 effective Aug. 1,2006) regulated short selling to allow short sales only when the current bid is equal to or greater than the current inside bid. Like the tick test, the bid test was developed in an attempt to stabilize the market by precluding shorts when prices are declining. The bid test allows more sales than the tick test, however, because "only the bid (rather than the actual price) must be rising for a short sale to be allowed." Nasdaq Securities Can Use Flexible Short Sale Rules, Fin. Srvs. Advisory Update (White \& Case LLP, New York, N.Y.), Aug. 2006, at 2, available at http://www.whitecase.com/publications/ detail.aspx?publication $=993$. 


\section{B. Recent Developments}

Notwithstanding these restrictions, the extent of short selling grew substantially, ${ }^{41}$ as did theoretical and empirical understanding of its social effects, resulting in a number of changes in SEC policy in recent years.

\section{The Rule 202T Test Suspension of Regulations}

In 2004, in the midst of a five-year period of strongly increasing stock prices, ${ }^{42}$ the SEC adopted Rule 202T of Regulation SHO, which established procedures for the SEC to suspend its short sale restrictions for a test set of issuers in order to perform a study comparing their pricing with issuers that continued to be subject to the restrictions. ${ }^{43}$ The test period ultimately ran from May 2, 2005 through August 6, 2007. Essentially, one-third of the three thousand issuers composing the Russell 3000 Index were selected at random to be the test group for whom restrictions were suspended, with the remaining two-thirds serving as a control group.

\section{Evaluation of the Test Results and Elimination of Restrictions}

The SEC had the staff at its Office of Economic Analysis ("OEA") analyze the data collected in connection with the test and made this data available to outside researchers as well. A recent SEC Release, looking back to the time following the conclusion of the test, states that "OEA found little empirical justification at that time for maintaining short sale price restrictions, especially for actively traded securities." ${ }^{\prime 4}$ The Release goes on to say that this analysis, combined with the studies of outside researchers, "generally ... supported removal of short sale price test restrictions at that time." ${ }^{5}$ Reflecting these findings, the SEC eliminated all restrictions on short selling effective July 3, 2007.46

\section{The Financial Crisis Reversal}

The sharp drop and high volatility displayed by market prices in the summer and fall of 2008, however, led the SEC to reverse course. It issued two temporary emergency orders relating to the short selling of financial issuer stocks-the first, in

41. Holger Daske, Scott A. Richardson \& Irem Tuna, Do Short Sale Transactions Precede Bad News Events? (The Wharton Sch., Univ. of Pa. 2005), available at http://papers.ssrn.com/sol3/papers.cfm?abstract $\mathrm{id}=722242$.

42. Four of the five years in the period 2003-2007 showed substantial growth in the Dow Jones Index and the decline in the year without growth, 2005, was a modest .61\%. The average annual growth during this five-year period was $10.12 \%$. 1Stock1.com, Dow Jones Industrial Average Yearly Returns, http:// www.1stock1.com/1stock1_139.htm (last visited Feb. 25, 2010).

43. Regulation SHO, 17 C.F.R. § 242.202T (2004).

44. Amendments to Regulation $\mathrm{SHO}$, supra note 34, at 13.

45. Id. at 15 .

46. Regulation SHO and Rule 10a-1, Exchange Act Release No. 34-55970, 72 Fed. Reg. 36,348 (July 3, 2007) (to be codified at 17 C.F.R. pts. 240, 242). 
July 2008, reinforced rules relating to the borrowing and delivery of shares ${ }^{47}$ and the second, in September 2008, prohibited, for a two-week period, all short selling of the shares of about 800 financial issuers. ${ }^{48}$ In April 2009, after continued trouble in the markets, the SEC proposed for comment the imposition of some new form of short sale price test or circuit breaker. ${ }^{49}$ In its release making these proposals, the SEC stated, "we are not aware of specific empirical evidence that the elimination of short sale price tests has contributed to the increased volatility in U.S. markets." ${ }^{50} \mathrm{It}$ suggested, however, that many members of the public believe that there is a connection, ${ }^{51}$ and that the resulting deterioration in investor confidence made proposing these reforms appropriate..$^{52}$

\section{EMPIRICAL RESEARCH}

What does the empirical research to date tell us about the theories relating to the possible social benefits and harms caused by short selling and the effects of the various regulatory interventions over the last seventy-five years? Until recently, this research was hampered by the fact that the only available data with respect to each issuer was its market's monthly statement of the level of short interest as of midmonth-i.e., the proportion of the issuer's outstanding shares that, as of that date, had been sold short and not yet been covered..$^{53}$ Recent research, however, has taken advantage of newly available daily data concerning short selling activity - the number of shares of an issuer sold in a day that are marked "short," which is the data used in our study as well. There is also recent research using detailed new data from the 1930s relating to regulatory events in that period.

\section{A. Research Seeking to Explain Monthly Short Interest}

The level of monthly short interest in an issuer's shares has been found to be positively related to a number of factors: (i) negative abnormal returns in the following month, ${ }^{54}$ (ii) high share prices relative to a variety of measures associated with

47. Emergency Order Taking Temporary Action to Respond to Market Developments, Exchange Act Release No. 34-58166, 73 Fed. Reg. 42,349 (July 15, 2008).

48. Emergency Order Taking Temporary Action to Respond to Market Developments, Exchange Act Release No. 34-58592, 73 Fed. Reg. 55,169 (Sept. 18, 2008).

49. Jones, supra note 34 , at 1 .

50. Id. at 17 .

51. Id.

52. Id. at 25 .

53. See Order Approving Proposed Rule Changes to Increase the Frequency of the Short Interest Reporting Requirements, Exchange Act Release No. 34-55406, 72 Fed. Reg. 11,071 (Mar. 6, 2007). FINRA Rule 4560, previous NASD Rule 3360 and Consolidated NYSE Rules 421(2) and 421.10, now require semimonthly reporting, but, prior to September 7, 2007, reporting under these rules was only required on a monthly basis.

54. Paul Asquith, Parag A. Pathak \& Jay R. Ritter, Short Interest and Stock Returns (Nat'1 Bureau of Econ. Research, Working Paper No. W10434, 2004), available at http://ssrn.com/abstract=532993; Hemang 
fundamental value, ${ }^{55}$ (iii) subsequent downward analyst revisions, ${ }^{56}$ and (iv) subsequent negative earnings surprises. ${ }^{57}$ These results suggest that, at least before accounting for transaction costs associated with short selling, short sellers can earn abnormal profits. These profits could be based on superior analysis and hence be consistent with the view that the practice has the socially beneficial effect of helping make share prices more accurate by adding to the incentives to gather and analyze information and the incorporation of the resulting conclusions into share price. More problematically, however, such profits could be based on inside information or they could be the product of the clearly socially harmful practice of spreading false news, which would be more directly related to our project.

\section{B. Research Concerning the Effects of Short Selling Restrictions on Share-Price Levels}

Determining the effect of short selling restrictions on the level of share prices of the issuers involved is important for sorting out the various theories discussed above concerning short selling's social effects, both positive and negative. One theory, relating to how short selling helps prices better reflect disparately spread information, suggests that restrictions on short selling bias prices upward to a level above their fundamental value..$^{58} \mathrm{~A}$ second theory, also relating to how short selling helps prices better reflect disparately spread information, suggests that restrictions would make prices less accurate but would not consistently bias them one way or the other. ${ }^{59} \mathrm{~A}$ third theory, relating to how short selling can be used by traders to engage in pure manipulation, implies that restrictions would inhibit a practice that, at least temporarily, biases prices downward. ${ }^{60}$

The empirical literature on the effect of short selling restrictions on share price levels is mixed in its conclusions. A study by Charles Jones, concerning various restrictions imposed in the 1930s, concludes that the respective impositions of restrictions were associated with a positive share-price reaction. ${ }^{61}$ This result is consistent with the first theory-that restrictions, by diminishing the influence of investors holding negative information, bias prices above their fundamental leveland the third theory - that the lack of restrictions, by making purely manipulative

Desai at al., An Investigation of the Information Role of Short Interest in the Nasdaq Market, 57 J. Fin. 2263 (2002).

55. Patricia M. Dechow et al., Short-sellers, Fundamental Analysis, and Stock Returns, 61 J. Fin. Econ. 77 (2001).

56. Jennifer Francis et al., Do Short Sellers Convey Information About Changes in Fundamentals or Risk? (Working Paper, on file with the Fuqua Sch. of Bus., 2005), available at http://ssrn.com/ abstract $=815668$.

57. Id.

58. See supra Part I.A.2.b.

59. See supra Part I.A.2.a.

60. See supra Part I.C.1.

61. Jones, supra note 34 
bear raids easier, biases prices below their fundamental level. But it is not consistent with the second theory - that restrictions do not consistently bias prices one way or the other, they just make them less accurate. The fact that the price reaction to each restriction occurred at the time that the rule became effective, rather than at the time it was announced, is also inconsistent with the rational expectations assumption behind the second theory.

On the other hand, a study of much more recent trading by Diether, Lee, and Werner comes to a different conclusion. ${ }^{62}$ This study analyzed data concerning the daily level of shorting activity and price behavior of issuers that composed the approximately 1000 issuers in the SEC's Rule 202T test group, for which, during the test period of May 2005 through August 2007, all short sale restrictions were eliminated, and compared it with the same data for the approximately 2000 issuers in the control group, on which the existing restrictions continued to be imposed. ${ }^{63}$ The authors found that the level of shorting activity for the test group increased relative to the control group, but that daily returns and volatility were essentially the same for each group. ${ }^{64}$ The test group's relative increase in shorting activity suggests that the restrictions were having a real effect on behavior. The lack of a statistically significant difference between the two groups in terms of returns is consistent with the second theory's implication that restrictions on short selling, though reducing price accuracy, will not bias prices, but is unsupportive of the first and third theories. The lack of a statistically significant difference with respect to volatility has ambiguous implications in terms of support for the second theory, because no consensus exists among financial economists concerning the relationship between volatility and share price accuracy. ${ }^{65}$

\section{Studies Relating Daily Shorting Activity to Abnormal Returns}

A substantial portion of short sales are covered in a matter of days. ${ }^{66}$ Studies of the relationship between short interest in the middle of one month and returns in the next month are thus likely to miss much of what animates such short sales and their effects. Recently available data concerning daily short sale activity, which we use in our study, provides a window into this matter. This data is based upon the proportion of an

62. Karl B. Diether, Kuan-Hui Lee \& Ingrid M. Werner, It's SHO Time! Short-Sale Price Tests and Market Quality, 64 J. Fin. 37 (2009).

63. Id.

64. Id. at $38-40$.

65. Compare Kenneth D. West, Dividend Innovations and Stock Price Volatility, 56 Econometrica 37 (1988) (The lower the volatility as measured by the variance ("SSE") of the portion of an issuer's daily share price change not explained by the day's return on the market as a whole, the more accurate the issuer's share price), and Randall Morck et al., The Information Content of Stock Markets: Why Do Emerging Markets Have Synchronous Stock Price Movements? 58 J. Fin. Econ. 215 (2000) (The higher the SSE relative to the variance of the issuer's total daily share price change, the more accurate the issuer's share price.). For a more detailed discussion of this point, see Merritt B. Fox et al., Law, Share Price Accuracy, and Economic Performance: The New Evidence, 102 Mich. L. Rev. 331, 350-57 (2003).

66. Diether, Lee \& Werner, supra note 4 , at 578-79. 
issuer's daily sales that are marked "short," as is required of brokers executing a short sale. ${ }^{67}$ Before the discussion of our study, in Parts IV and V, we review here the existing studies using such data. This review will help in the interpretation of our results.

\section{Christophe, Ferri, and Angel-Short Sales Preceding Earnings Announcements}

Christophe, Ferri, and Angel ("CFA") examined daily short trading activity of the more established NASDAQ issuers from September 13, 2000 to December 12, 2000, and related this level of activity to the timing of issuer earnings announcements. ${ }^{6}$

a. Findings. CFA found that the level of short activity in the five days preceding an earnings announcement is different from the level at other times. ${ }^{69}$ The level is unusually low in advance of positive earnings surprises and unusually high in advance of negative earnings surprises. ${ }^{70}$ Moreover, the level of short selling is inversely related to the post-announcement price reaction, ${ }^{71}$ and so the extent of the deviation in each direction from the normal level of short selling was found to be related to the extent of the earnings surprise. CFA concluded that these results are "consistent with the existence of informed traders engaging in abnormally large short selling as they anticipate a negative earnings surprise and a corresponding decline in share price." 72

CFA made the additional determination that during trading days outside this brief window before an earnings announcement, there is an above-average level of short selling for shares of issuers with characteristics that, according to some parts of the finance literature, are more likely to have what, to the market, turns out to be a negative surprise concerning earnings. However, CFA found that these issuers still had an increase in short selling activity during this brief window relative to their already-elevated level at other times. On the basis of this additional determination, they concluded that "pre-announcement behavior is more likely to be driven by information specific to the upcoming announcements of the individual firms,"73 presumably in contrast to gathering and analyzing publicly available data in order to detect a deviation between price and fundamental value. Such specific information about upcoming announcements is, of course, confidential and can only come, directly or indirectly, from persons inside the firm.

b. Interpretation: The importance of short selling based on inside confidential information. Even absent this additional determination, CFA's conclusion that inside information motivated the observed short selling increase during this brief period in advance of

67. See Regulation SHO, 17 C.F.R. § 242.200 (2009).

68. Stephen E. Christophe, Michael G. Ferri \& James J. Angel, Short Selling Prior to Earnings Announcements, 59 J. Fin. 1845 (2004).

69. Id. at 1845 .

70. Id. at 1846 .

71. Id.

72. Id. at 1873

73. Id. at 1846 . 
earnings announcements with negative surprises makes sense on its face. Because new events relevant to predicting an issuer's future cash flows are occurring all the time, a deviation between price and fundamental value-the development that creates a profitable opportunity for gathering and analyzing publicly available information and trading on the conclusion-can occur at any time. Thus, there is no reason to believe that the expected return-and hence the level of short selling activity-from gathering and analyzing publicly available information would be sharply higher during the few days immediately preceding a quarterly earnings announcement than during all the other trading days of the quarter.

The findings that shorting activity is lower than normal in advance of a positive earnings surprise, and that the more positive the surprise, the lower the level of short selling, have additional implications not explored by CFA. Namely, if short selling is lower than normal immediately in advance of a positive earnings surprise, the deficit has to come from the absence of short sales by members of the class of persons who, during all the other trading days of the quarter, would have sold the issuer's shares short but who do not do so because they have information concerning the announcement.

CFA's finding thus suggests something about the proportion of persons that make trading decisions based on inside confidential information out of the larger group of all persons who are regularly engaging in short selling. This proportion is large enough that at the moments when we would expect such traders to be particularly likely to possess material inside information-just before announcements of positive earnings surprises-we can observe a dip in short selling that is large enough to be statistically significant, despite the background noise from changes in level of short selling activity by the traders in the market who are not trading on the basis of inside information. This finding is all the more interesting because a person who has access a few days in advance to inside information about an issuer's positive earnings announcement is likely to be a person who is also able, at times other than immediately in advance of an earnings announcement, to obtain nonpublic inside information about earnings and other matters relevant to predicting an issuer's future cash flows. The CFA finding thus suggests that a significant portion of short selling at all times of the year, not just in advance of quarterly earnings announcements, is motivated by inside information.

\section{Deither, Lee, and Werner-Short Sales Preceding Abnormal Returns}

Deither, Lee, and Werner ("DLW") examined daily short trading activity in 3854 NYSE and NASDAQ listed issuers from January 2, 2005 until December 30, 2005 , and related it to the timing of issuers' abnormal returns. ${ }^{74}$

a. Findings. DLW's first finding relates to short selling activity in advance of daily price changes in an issuer's shares that represent abnormal returns. They found

74. See Diether, Lee \& Werner, supra note 4. 
that short selling activity increases in the five days preceding negative abnormal returns. ${ }^{75}$

b. Likely explanations. There are three kinds of short selling that in the aggregate most likely explain DLW's finding: (i) traders selling short on inside information concerning an upcoming issuer announcement, (ii) traders who spread false negative information about an issuer and then short sell, and (iii) traders who spread true negative information about an issuer and then short sell.

i. Near-announcement inside-information short sellers. Consider a trader (a "near-announcement inside-information short seller") who obtains confidential information, directly or indirectly from inside an issuer, that the issuer is about to announce significantly negative news. The trader seeks to profit from this information by selling the issuer's shares short. Immediately after the public announcement of the bad news, the issuer's share price will often decline sufficiently to represent an abnormal negative return. This trader cannot sell on the basis of the inside information until she receives it, which, by our definition, is only a few days before the announcement. The short sales of this trader would elevate the aggregate level of short selling in the issuer's shares above what it otherwise would be. Because, in an efficient market, the announcement of bad news would have an immediate negative share price effect that would often represent an abnormal negative return, the existence of such traders would help explain the DLW finding of an elevated level of short selling during the five days preceding a negative abnormal return. As noted earlier, their behavior is in many instances illegal and, in the view of most commentators today, socially harmful. ${ }^{76}$

For a number of reasons, a significant portion of all the short selling based on confidential information from inside an issuer that is relevant to predicting a future negative announcement is likely to occur within the five days preceding the announcement. To start, a message containing this information is less risky to trade on when it is received soon before the predicted announcement. The message on its face is likely to be a higher probability prediction that the announcement will in fact occur. Also, the prediction will be more credible because the person delivering the message has the reputational concern that it will be subject to rapid and unambiguous confirmation or refutation. For the same reasons, the message is more likely to spread easily among traders. This spread is further aided by the fact that the message is likely to be more discrete and specific than information that suggests the implications of a possible announcement some time further in the future. The broader the spread of the message, the more it likely will add to the volume of short sales.

One prominent kind of bad news announced by an issuer that is likely to be followed by an abnormal negative return is, of course, a negative earnings surprise. Thus, the near-announcement inside-information short selling explanation of DLW's

75. Id. at $576-77$.

76. See supra Part I.D. 
finding is consistent with the inside-information explanation of the CFA results provided above.

ii. False-neww-spreading short sellers. The universe of events studied in the DLW study-abnormal negative returns-is much broader than the issuer-announced earnings surprises studied by CFA. As a result, the range of possible explanations is expanded as well. One additional possible explanation is that traders who short sell soon thereafter spread false negative news in some way that seems credible to a sufficient number of traders to bring the price down, and then cover at the depressed price. We will refer to such traders as "false-news-spreading short sellers." These traders would be anxious to time their short sales and the spreading of the false news close together, so as to cover at the depressed prices as quickly as possible and thereby minimize their risk and lock in their profits. Thus, when the tactic is sufficiently successful, an abnormal negative return would be expected to be observed within a few days of the elevation in short sales caused by such traders, which is consistent with the DLW finding. As noted earlier, this behavior is illegal and unambiguously socially harmful. ${ }^{77}$

iii. Fundamental-analysis true-nerws-spreading short sellers. A third possible explanation of DLW's finding is that the existence of traders who gather and analyze bits of publicly available information sell short when they detect that price exceeds fundamental value and then truthfully communicate their conclusions to someone in the media with the hope of generating a price decline that will allow them to cover at a profit ("fundamental-value true-news-spreading short sellers"). Where the trader is credible to a person in the media, the person in the media is credible to the trading public, and the conclusion involves discrete information relevant in some significant way to predicting an issuer's future cash flows, one would often expect an abnormal negative return to result. Again, the trader, to minimize her risk and lock in her profits, would want, as soon as possible after she completes her short sales, to prompt the decline in price and to cover. As soon as the short sales are complete, therefore, she would communicate her conclusion to a media person. If the media person finds the conclusion credible, she would rush to be the first to get the story out. Thus, again, the abnormal negative return would be expected to be observed within a few days of the elevation in short sales caused by such traders. Unlike the other two explanations of the DLW finding, however, it is not illegal for a short seller to base trades on this kind of information or truthfully to communicate her conclusions to a person in the media. Also, this behavior unambiguously helps to improve share price accuracy, with the accompanying social benefits. ${ }^{78}$

77. See supra Part I.C.4. The fact that these short sales are illegal may have a countervailing tendency on a desire of traders otherwise to time the short sales and the spreading of the false news as closely together as possible. Concern over detection may prompt the traders to spread the short sales over a longer period of time before spreading the false news despite the increased financial risk.

78. See supra Part I.A. 
iv. Importance of these three kinds of trading. As discussed immediately below, none of the other kinds of short selling that we can identify appear to be likely explanations of the DLW finding. Thus, the DLW finding suggests that the three kinds of trading already discussed, in the aggregate, exist in sufficient amounts above and beyond the other kinds of short selling discussed below that when they occur, they are statistically significant. DLW's study does not, however, contain any information concerning the relative importance of these three kinds of short selling.

c. Short selling activity that does not explain the DLW finding. We can identify three other kinds of short selling: (i) portfolio-adjusting short selling, (ii) fundamentalanalysis non-news-spreading short selling, and (iii) distant-announcement inside-information short selling. None of these likely explain the DLW finding.

i. Portfolio-adjusting short sellers. "Portfolio-adjusting short sellers" are persons who sell short for portfolio adjusting reasons such as hedging, liquidity provision, or other risk-related reasons. These short sales are unrelated to information or news. Because abnormal returns typically reflect the incorporation of new information into prices, the timing of these short sales should not be associated with the timing of abnormal returns. Trades based on these motives are not illegal and they serve socially useful purposes.

ii. Fundamental-analysis non-news-spreading short sellers. "Fundamentalanalysis non-news-spreading short sellers" are traders who gather and analyze bits of publicly available information, sell short when they detect that price exceeds fundamental value, and profit by covering after the price declines with the disappearance of the deviation. These short sales are similarly not illegal and they are unambiguously socially beneficial in terms of improving share price accuracy. They also cannot explain the DLW result. The fundamental-analysis trader who sells short and then truthfully communicates her conclusion to someone in the media in a way that results in a significant price change, discussed above as a possible explanation of DLW's finding, is a special case. This special case requires that the fundamental analysis trader's conclusion involves discrete information relevant in some significant way to predicting an issuer's future cash flows, that the trader has credibility, both as to her honesty and her skill in fact-gathering and analysis, and that this credibility be with a person in the media who in turn has credibility with the trading public. Outside of this special case, the rest of short selling motivated by fundamental analysis will not explain the DLW finding.

To see why much of fundamental-analysis-based short selling will not explain DLW's finding, consider the ways, outside of the special case, that the deviation between share price and fundamental value detected by a short seller can disappear. One way is for an issuer to make a public announcement that reveals the underlying reality about the issuer's situation that the short seller detected. Such an announcement would often generate an abnormal negative return.

Typically, however, the short sale based on a trader's detection of the deviation would have occurred more than five days earlier. This is because the change in 
fundamental value that originally generated the deviation would in most cases have developed more than five days in advance of the public announcement. Where the deviation exists well before the announcement, so does the opportunity to profit from detecting it. Thus there is no reason to believe that the expected return from information gathering, analyzing, and trading on the conclusion, and hence the level of this activity, would be significantly higher in the few days immediately preceding the public announcement that ends the deviation than at any other point in time during the period that the deviation persists. So the elevation in short sales associated with these kinds of trades would not be expected to be concentrated in the few days immediately preceding the announcement that finally clarifies the situation and the accompanying abnormal negative return. Such trades, therefore, even when the deviation motivating them is eliminated by an issuer announcement generating a negative return, are not what are being picked up in the DLW finding.

A second way for the deviation between price and fundamental value detected by the short seller to disappear is the result of trading activity by other traders when they subsequently privately learn, directly or through trade decoding, of the first short seller's analysis, or when they engage in similar gathering and analysis and come to the same conclusion. This process would not typically result in a discrete price reaction resulting in an abnormal return on a single day and thus also would not explain DLW's findings, which relate abnormal returns to immediately preceding elevated levels of short sales.

A third way for the price deviation detected by the short seller to disappear is when the events predicted by the short seller's changed evaluation become publicly known and reflected in price without an issuer announcement. For the same reasons as when the deviation disappears because of an issuer public announcement, this process would typically take longer than five days. Moreover, public awareness might occur slowly and therefore not even generate a large enough negative return on any given day for the returns that were observed for the day to be likely to be considered abnormal.

iii. Distant-announcement inside-information short sellers. We argued earlier that a significant portion of short selling based on confidential information from inside an issuer that is relevant to predicting a future negative announcement occurs within the five days preceding the announcement. There are also many instances, though, where such confidential information becomes available to traders more than five days in advance of the announcement and becomes the basis of a short sale soon after receipt ("distant-announcement inside-information short sellers"). Any abnormal negative return that accompanies the announcement when it is finally made would therefore be more than five days after the elevation in the aggregate level of short sales resulting from such trades and therefore could not explain the DLW finding. Of course, the price might drop in advance of the announcement as the result of sales by other traders when they either subsequently privately learn, directly or through trade decoding, of the first short seller's information, or when they receive the information from the inside themselves. This process would not typically result in a 
discrete price reaction resulting in an abnormal return on a single day, and thus also would not explain the DLW finding. This stretching out of the price impact is especially likely because of the legal risks associated with trading on such information or passing it to others.

\section{THE STUDY}

Our study examined whether there is evidence of a relationship between significant news about an issuer in the media and the level of short selling of its shares. This news is likely to have come to the media from one of four sources: (i) the issuer itself or its insiders, (ii) research based on gathering and analyzing publicly available bits of data by a person who is not involved in trading in the issuer's securities in advance of the news or in giving private advice to someone who is doing so, (iii) research based on gathering and analyzing publicly available bits of data by a person who is trading in the issuer's securities in advance of the news or is giving advice to someone who is, and (iv) someone who spreads false news in order to trade in the issuer's shares in a way that takes advantage of the impact of the false news on the price of the shares.

\section{A. Short Selling Data}

Our sample of short selling activity consisted of two subsamples. The first subsample came from NYSE data and covered daily short selling activity for all NYSE stocks from the period January 3, 2000 to September 30, 2002. The second subsample of short sales data starts on January 3, 2005 and ends on July 6, 2007, beginning just before Rule 202T's implementation and ending just before the pilot ended. These short sales data consist of approximately 3000 test and control firms in the Rule $202 \mathrm{~T}$ test. $^{79}$ The number of issuers experiencing at least some shorting activity on a given day in our sample ranged from 1930 to 2625 , and gradually increased over time. There were in total approximately 2.3 million firm days in the sample.

Our source of news about each of the issuers in the sample was the Dow Jones Newswires. Thus, for a story, whether true or false, to be detected as news in our study, it had to be sufficiently credible and broadly spread such that it was picked up by, or influenced the opinion of, either someone in the media or an analyst or other commentator who is covered by the media. A day was defined as the period from the close of the market on one calendar trading day until the close of the market the next calendar trading day. Out of the 2.3 million firm days in our sample, there was news in about 416,000 , or $18 \%$. In 114,000 of these, the only news about the issuer arrived during the trading hours of a day (9:30 a.m. to 4:00 p.m.). In 232,000 of these, the only news about the issuer arrived during the day's pre-market, non-trading hours (from 4:00 p.m. of the immediately preceding calendar day on which there had been trading to 9:30 a.m. when trading began again). In the remaining 70,000 cases, news

79. See supra Part II.B.1. 
arrived about the issuer during both the trading hours of a day and the day's premarket hours.

\section{B. Measure of the Content of the News}

Our measure of the content of the news related to the percentage of total words in an article about an issuer that were designated as negative. ${ }^{80}$ The list of words that were determined to be negative was based on the Harvard-IV-4 psychosocial dictionary $^{81}$ and a financial negative-word list developed by Loughran and McDonald. ${ }^{82}$ This type of content analysis approach, using the Harvard-IV-4 dictionary to analyze the import of text in the media, has been employed before both in finance literature ${ }^{83}$ and in the social sciences more generally. ${ }^{84}$ In our study, all the words that were on the list of negative words were considered to be equally important-i.e., equally negative-and all other words were considered to be uninformative. The negativity of a news story was measured by the percentage of words in the story that were negative according to the two lists. ${ }^{85}$ This measure of negativity is obviously crude, but it has no obvious bias. Indeed, its noisiness would work against our finding a result. Counteracting the noisiness of the measure is the fact that the number of observations that we employed was huge, from the tens to hundreds of thousands, depending on the test.

Tetlock, Saar-Tsechansky, and Macskassy ("TSM") have previously used the Harvard-IV-4 dictionary to measure the content of media reports about individual issuers. TSM showed a statistically significant relationship between the level of

80. We identified an article containing news about an issuer by using the Dow Jones ticker codes in the article header. Each issuer with a Dow Jones ticker code in the article header received the same negative word count. We restricted the sample to articles mentioning either one or two firms, in order to increase the likelihood that the news was relevant for the firms included in the article header. To increase the likelihood that the article had some relevance for firm valuation, we used only articles containing at least twenty-five words in total and at least one of the following words: "press release," "earn," "net income," "profit," "sales," "revenue," "trade," “buy," “sell," "gain,” "loss," “rumor," "analyst," and common alternative forms of each such word.

81. Harvard-IV-4 Dictionary, Internet General Inquirer, http://www.webuse.umd.edu:9090/tags/TAGNeg. html (last visited Feb. 28, 2010) (listing each word in the negative category).

82. Tim Loughran \& Bill McDonald, When is a Liability not a Liability? Textual Analysis, Dictionaries, and 10-Ks, J. Fin. (forthcoming), available at http://papers.ssrn.com/sol3/papers.cfm?abstract_id=1331573.

83. See Paul C. Tetlock, Giving Content to Investor Sentiment: The Role of Media in the Stock Market, $62 \mathrm{~J}$. Fin. 1139 (2007); Paul C. Tetlock, Maytal Saar-Tsechansky \& Sofus Macskassy, More than Words: Quantifying Language to Measure Firms' Fundamentals, 63 J. Fin. 1437 (2008).

84. For a survey, see Daniel Riffe, Stephen Lacy \& Frederick G. Fico, Analyzing Media Messages: Using Quantitative Content Analysis in Research (Lawrence Erlbaum Associates 1998).

85. Our final negative measure equals two-thirds times the percentage from the financial negative word list plus one-third times the percentage from the Harvard-IV-4 list. The weightings are designed to offset the fact that words on the Harvard-IV-4 list occur approximately twice as often as words on the financial negative-word list. Aside from these weightings, all the words that are on the negative-word lists are considered to be equally important-i.e., equally negative-and all other words are considered to be uninformative. 
negativity in media reports about an issuer and subsequent returns on the issuer's shares. ${ }^{86}$ Specifically, the TSM study found that stock market prices respond to the information imbedded in negative words with a small one-day delay. ${ }^{87}$ They also found that, even after controlling for analysts' forecasts and historical accounting data, the relative frequency of negative words predicts subsequently reported firm earnings. ${ }^{88}$ This second finding suggests that the frequency of negative words contains meaningful additional information relevant to better predicting an issuer's future cash flows.

\section{RESULTS AND INTERPRETATION}

Consider Day 0 to relate to a calendar day on which there has been trading. Day 0 was defined as the period that ran from the 4:00 p.m. close of trading on the immediately preceding calendar day on which there had been trading through to the close of trading at 4:00 p.m. on the calendar day to which Day 0 relates. Day 1 was the similarly defined period running from the end of Day 0; Day 2 the similarly defined period running from the end of Day 1. To illustrate, suppose a Friday and the succeeding Monday, Tuesday, and Wednesday were all trading days and Day 0 related to the Monday. Day 0 would run from the preceding Friday at 4:00 p.m. to Monday at 4:00 p.m.; Day 1 would run from Monday at 4:00 p.m. to Tuesday at 4:00 p.m.; and Day 2 would run from 4:00 p.m. on Tuesday to 4:00 p.m. on Wednesday. Day 0 was subdivided into its pre-market hours $(4: 00$ p.m. of the immediately preceding calendar day on which there had been trading until 9:30 a.m. of the calendar day to which Day 0 relates) and the trading hours (the remainder of Day 0, running from 9:30 a.m. to 4:00 p.m. of the calendar day to which Day 0 relates). Day 1 and Day 2 were similarly subdivided.

\section{A. Abnormally High Short Selling in Day 0}

Our first major finding is that when, during the trading hours of Day 0 , there is an abnormally high level of short selling in an issuer's shares (relative to the preceding nine trading days), the news concerning the issuer in the pre-market hours of Day 1 is more negative than average. This finding persists even after controlling for the tendency of negative news during Day 0 to foreshadow the negative news on Day $1 .{ }^{89}$

86. Tetlock et al., More than Words, supra note 83, at 1439.

87. $I d$.

88. $I d$.

89. We implemented this test using a linear regression of news negativity on abnormal short selling activity. Table 1 reports the coefficients and standard errors from two such regressions. We measured short selling (short_0) in the trading hours of Day 0 and news negativity (pre_neg_1) in the pre-market hours of Day 1. Key control variables include percentage news negativity in the pre-market and trading hours in Day 0 (pre_neg_O and trad_neg_O), the firm's market-adjusted stock returns (abret_O), its abnormal trading volume (volm_o), and its market capitalization (size_o). The standard errors of the regression coefficients adjusted for correlations among different firms' stock returns in the same day. The coefficient on the short_ $O$ variable measured the ability of short selling on Day 0 to predict pre-market news negativity on Day 1 . In the first regression in Table 1 , which contains the entire sample, the short_o 


\section{Kinds of Short Selling that Explain the Finding}

This first major finding is likely the result of one or more of the three kinds of short selling-near-announcement inside-information short selling, false-newsspreading short selling, and fundamental-analysis true-news-spreading short selling - that also constitute the likely explanations of DLW's first finding.

There are good reasons to believe that the short sales of near-announcement inside-information short sellers would, relative to other days, occur more frequently in the trading day immediately before the issuer's announcement of the information on which the short sellers are trading. Many of the short sales based on this information will not occur before this point because the short sellers do not receive the information until then, at least not in sufficiently reliable form. Also, even when a trader receives this information in reliable form earlier, she may postpone her short sale based on it until just before the announcement in order to minimize the time between the short sale and the time of cover. Doing so minimizes the risks associated with other factors that move the issuer's share price around over time..$^{90}$

For similar reasons, false-news-spreading short sellers and fundamental-analysis true-news-spreading short sellers will also each be expected to be more concentrated right before the announcement of the news that they spread. Such traders will want to postpone their short sale until just before spreading the news, again in order to minimize risk by minimizing the time between the short sale and the time of cover.

\section{Kinds of Short Selling that Do Not Explain the Finding}

None of the three remaining kinds of short selling that we have identifiedportfolio-adjusting short selling, fundamental-analysis non-news-spreading short selling, and distant-announcement inside-information short selling-is likely to help explain our first major finding.

Because portfolio-adjusting short selling is unrelated to information, there is no reason to think it would be concentrated in advance of news in the media about an issuer. As for fundamental-analysis non-news-spreading short selling, the deviation between share price and fundamental value that is detected by the trader and prompts the short sale may ultimately be dissipated as the result of news in the media. But, for the reasons discussed earlier concerning why such traders do not explain DLW's first finding, there is no reason to think that detection of such deviations, and the resulting

coefficient is equal to $0.04 \%$ and is marginally statistically significant at the $5 \%$ level (p-value $=0.061$ ). See infra Table 1.

The next two regressions divide the sample into two subsamples where we separately analyze the cases in which short selling is above average (short_O $>0$ ) and below average (short_O $\leq 0)$. In the aboveaverage short selling sample, set out in the second column of Table 1 , the short_ 0 coefficient is equal to $0.18 \%$ and is statistically significant at any conventional level (p-value $<0.001)$. In the below-average short selling sample, when short_O is less than zero, set out in the last column in Table 1 , the regression coefficient of pre_neg_1 on short_O is significantly negative (p-value $=0.004)$. See infra Table 1 .

90. See supra notes $32-33$ and accompanying text. A countervailing force would be the desire to use the information ahead of possible trading by others based on the same information, thus avoiding the price effects of the other trades. 
short sales, would be concentrated right before this news story. ${ }^{91}$ Moreover, the deviation may well disappear without there ever being a news story relating to it, either through the price effect of the sales of other traders who also become aware of the deviation or as the result of gradual public awareness of the true situation. ${ }^{92}$ As for distant-announcement inside-information short sellers, news related to the announcement would, by definition, not occur immediately after the short sales.

\section{Further Evidence Concerning the Importance of the Kinds of Short Selling Explaining the Finding}

Related results from our study tend to confirm the importance of nearannouncement inside-information short sellers, false-news-spreading short sellers, and fundamental-analysis true-news-spreading short sellers and their role in explaining our first major finding. We find, consistent with DLW, that aboveaverage short selling of an issuer's shares during the trading hours of Day 0 predicts below-average returns during the trading hours of Day 1. But we also find that this ability of the level of short selling to predict the next day's returns is greater when there is pre-market news on Day 1 concerning the issuer than where there is no news concerning the issuer during these pre-market hours. ${ }^{93}$

The relevance of these results to our first major finding can be seen as follows. Short selling on Day 0 might be elevated for one of two reasons. One reason is stochastic variation in the level of portfolio-adjusting short selling, fundamental-analysis nonnews-spreading short selling, or distant-announcement inside-information short selling. The other reason is an increase in near-announcement inside-information short selling, false-news-spreading short selling, or fundamental-analysis true-newsspreading short selling. When the elevation in the aggregate level of short selling is due to the first reason, one would not expect it to predict below-average returns the next day. Nor would it predict the existence of news about the issuer in the next day's premarket hours. In contrast, when the elevation is due to the second reason, one would expect such short selling to predict the next day's returns. Moreover, there is also more likely to be news about the issuer because these kinds of short selling are either made in anticipation of such news or are actually tied to prompting it. Our results-that when there is news about the issuer in the pre-market hours of Day 1, elevated short

91. See supra Part III.C.2.c.ii.

92. See supra Part III.C.2.c.ii.

93. The columns in Table 2 report the results from two regressions predicting the firm's market-adjusted returns on Day 1 (abret_1) using abnormal short selling activity on Day 0 (short_O) and other variables. Both regressions include an interaction term between abnormal short selling activity on Day 0 and the presence of pre-market news on Day 1 (short_O* pre_news_0). The economically and statistically significant ( $\mathrm{p}$-values < 0.01) negative interaction coefficients show that short selling on Day 0 is a better predictor of stock returns on Day 1 when the firm experiences a pre-market news event on Day 1 . In the second specification with additional control variables, a 100\% increase in short selling (relative to daily volume) predicts a return that is 17 basis points below average when there is no news on Day 1 , whereas it predicts a return of 41 basis points below average when there is news on Day 1. See infra Table 2. 
selling in Day 0 better predicts below-average returns in Day 1-are consistent with these expectations.

\section{The Relative Roles of the Kinds of Short Selling that Do Explain the Finding}

Related results from our study also hint at the relative roles of the three kinds of short selling that could plausibly explain our first major finding. These related results suggest that traders who sell short and then spread news, whether true or false, play a significant explanatory role. Specifically, we observe from our first major finding that when short selling is above normal on Day 0 , there is a positive, highly statistically significant relationship between the level of short selling on Day 0 and the negativity of news in the pre-market hours of Day 1 (see the second regression in Table 1). ${ }^{94}$ In contrast, we find that when the level of short selling is below normal on Day 0, there is not a positive relationship between the level of short selling during the trading hours of Day 0 and the level of negative news in the pre-market hours of Day 1 (indeed, as the third regression in Table 1 shows, it is negative). ${ }^{95}$

Our explanation of why we find a positive relationship between the level of short selling and the negativity of the news when short selling is above average, but do not find this result when short selling is below average, depends on combining it with the twin findings of CFA - that short selling activity in the five trading days preceding a positive earnings announcement surprise was below-normal and that it was unusually low in advance of an unusually large positive surprise-and with the fact that a below-normal level of negative news represents positive news. ${ }^{96}$

Imagine two worlds. In the first world, there is no short selling during the trading hours of Day 0 by persons who would then spread news during the pre-market hours of Day 1 -i.e., there are no false-news-spreading short sellers and no fundamentalanalysis true-news-spreading short sellers. Short selling would come from the other four groups of traders. As just noted, we would not expect to find a positive relationship between the level of short selling during the trading hours of Day 0 and the level of negative news during the pre-market hours of Day 1 for three of these four groups: portfolio-adjusting short sellers, fundamental-analysis non-newsspreading short sellers, and distant-announcement inside-information short sellers.

We would, however, expect to find a positive relationship between the level of near-announcement inside-information short selling during the trading hours of Day 0 and the level of negative news during the pre-market hours of Day 1 . This would not just be unusually high levels of short selling preceding unusually negative news;

94. The $\mathrm{t}$ statistic is 4.40 . In other words, we can reject with greater than $99.9 \%$ confidence the hypothesis that the results showing this relationship are due only to chance. See supra note 89.

95. See supra note 94 .

96. TSM found that tests measuring the relative optimism or pessimism of news articles using both words designated as positive in the Harvard-IV-4 psychosocial dictionary and words designated there as negative produce very similar results to the test, employed here, that simply uses negative words. Tetlock, Saar-Tsechansky \& Macskassy, supra note 83, at 1442. Putting this comparison of tests a different way, it suggests that if an article has a below-normal level of negative words, it is likely to have an abovenormal level of positive words. 
it would also be unusually low levels of short selling preceding unusually positive news. This latter expectation arises from the CFA finding that unusually low levels of short selling activity immediately precede unusually large positive earnings surprises-thus suggesting that unusually low levels of short selling by this group during the trading hours of Day 0 would be followed by an unusually low level of negative news in the pre-market hours of Day 1 . When the level of short selling is below average, however, we in fact do not find such a positive relationship between the level of short selling and the negativity of the news that follows.

The second world is the same as the first world except that instead of leaving out false-news-spreading short sellers and fundamental-analysis true-news-spreading short sellers, we leave out near-announcement inside-information short sellers. Again, we would expect not to find a positive relationship between the level of short selling during the trading hours of Day 0 and the level of negative news during the pre-market hours of Day 1 for three of the five groups: portfolio-adjusting short sellers, fundamental-analysis non-news-spreading short sellers, and distantannouncement inside-information short sellers. As for false-news-spreading short selling and fundamental-analysis true-news-spreading short selling, there would probably be no such short selling on most days for the typical issuer. But on occasional days there would be. On these occasional days, when there are news-spreading short sellers, the negative news that they spread in the pre-market hours of the next trading day would add to any existing negative news about an issuer. For the rest of the days, when there is no such short selling, the level of negative news about the issuer in the pre-market hours of the next trading day would be determined by other factors.

Suppose that in this second world, on the occasional day when either type of news-spreading short selling occurs, it adds substantially to the total number of short sales that day. On the other days, when there is no news-spreading short selling in an issuer's shares, the amount of short selling would therefore typically be below average (the average being boosted by the substantial extra short sales on the days when there is news-spreading short selling). And on the days when there is no news-spreading short selling, the level of negative news in the pre-market hours of the next trading day would be unrelated to the factors that lead to other types of short selling. On the occasional day where there is news-spreading short selling, the level of short selling would typically be above average and the level of negative news in the pre-market hours of the next trading day would be determined in part by the news that these short sellers spread. In this second world, we would expect that the pattern of short sales and next-day news would resemble what we observe in our study: the existence of a positive, statistically significant relationship between the level of short selling during the trading hours of Day 0 and negative news in the pre-market hours of Day 1 when short selling activity is above average, but no such positive relationship between the two when the short selling activity is below average.

These two worlds are of course somewhat stylized and our account does not include an explanation of why the below-average short selling results do not just show an absence of a positive relationship between the level of short selling and the negativity of the news that follows, but also the existence of an actual negative 
relationship. Nevertheless, the fact that our results do not resemble what we would expect to see if we were operating in the first world tells us something about the real world where near-announcement inside-information short selling, false-newsspreading short selling, and fundamental-analysis true-news-spreading short selling are all possible. The results at least hint that the latter two, in some combination, play a significant role worthy of detailed study. This is particularly so because falsenews-spreading short selling is unambiguously socially harmful, whereas fundamental-analysis true-news-spreading short selling results in a socially beneficial improvement in share price accuracy.

\section{B. The Effect of Day 0 Short Selling on Day 1 Price Reaction to Pre-Market Negative News}

\section{Finding}

Our second major finding is that when the news concerning an issuer in the premarket hours or trading hours of Day 1 has higher negativity than average news, the negative price reaction during the trading hours of Day 1 is smaller if, during the trading hours of Day 0, there was an abnormally high level of short selling of the issuer's shares (relative to the preceding nine days). ${ }^{97}$

\section{Types of Short Selling that Potentially Explain the Finding}

This second major finding can yet again be the result of any one or more of the three kinds of short selling that constituted the likely explanations of our first major finding: near-announcement inside-information short selling, false-news-spreading short selling, and fundamental-analysis true-news-spreading short selling. Also again, none of the other three kinds of short selling that we have identified is likely to help explain this second major finding.

\section{Explanation}

Consider the following explanation of this second major finding. Market participants on Day 1 have some idea of the level of short selling in an issuer's stock

97. This finding persists even after controlling for the tendency for unusually negative news during Day 0 to foreshadow unusually negative news on Day 1 . Column one in Table 3 displays the results from a linear regression in which we introduce interaction terms $(($ short_O $>0) *$ pre_neg_ 1 and $($ short_O $>0)$ * trad_neg_1) between above-average short selling on Day 0 (short_O $>0$ ) and pre-market negativity (pre_neg_1) or trading hours negativity (trad_neg_1) on Day 1 to measure this effect. The dependent variable in this test is the firm's market-adjusted return on Day 1 (abret_1). The regression includes control variables for short selling activity on Day -1 and negativity in the pre-market and trading hours of Day -1, among other variables. When short selling on Day 0 is equal to its average, the firm's abnormal return on Day 1 is 13.7 basis points below normal when pre-market negativity on Day 1 is $1 \%$ above average. When short selling on Day 0 is above average, the firm's abnormal return on Day 1 is 11.2 basis points (= 13.7 bps -2.5 bps) below normal when pre-market negativity on Day 1 is $1 \%$ above average. The abnormal return response on Day 1 to a $1 \%$ increase in negativity during the trading hours of Day 1 declines from -17.3 basis points to -13.0 basis points (= $17.3 \mathrm{bps}-4.3 \mathrm{bps}$ ) when short selling on Day 0 is above average. In both cases, the difference in the return response is statistically significant at the $5 \%$ level (p-values $=0.028$ and 0.004). See infra Table 3. 
on Day 0. When market participants observe an unusually high aggregate level of short selling on a given day, they know there is an increased chance that one of the three explanatory kinds of short selling is occurring. ${ }^{98}$ The increased likelihood that any of these three kinds of short selling occurred during the trading hours of Day 0 will, for the reasons discussed below, lead participants to discount the importance of negative news during the pre-market hours of Day 1, and thus its price impact during the trading hours of Day 1.

a. Near-announcement inside-information short selling. To isolate the effect of nearannouncement inside-information short selling, suppose that there was no possibility of false-news-spreading short selling or fundamental-analysis true-news-spreading short selling. Suppose also that a piece of negative news, with a given downward implication in terms of predicting an issuer's future cash flows, becomes public during the pre-market hours of Day 1.

Imagine two worlds. In the first world, there is no near-announcement insideinformation short selling, perhaps because there are very effective legal rules against insider trading, tipping, and trading on tipped information. In the first world, the level of short selling on Day 0 would be determined stochastically, independent of any news to be announced on Day 1, and we would therefore not expect to see any relation between the level of short selling and the price reaction to the negative news on Day 1.

In the second world, there is such short selling: negative confidential inside information does sometimes leak out and becomes the basis of short sales. Other times, however, negative confidential inside information does not leak out before it is announced. There is also information external to the firm but that is relevant to predicting future cash flows and is not traded on before its public availability. In this second world, when there is negative news in the pre-market hours of Day 1, we would expect to see a relationship between the level of short selling during the trading hours of Day 0 and the price reaction to this negative news on Day 1 . This is because sometimes in the second world, negative news that becomes public in the pre-market hours of Day 1 reflects inside confidential information that has leaked out earlier and become the basis of short selling during the trading hours of Day 0 . When this happens, the level of short selling would, on average, be abnormally high because there would be short sales based on this leaked information in addition to all the normally occurring short sales motivated by other considerations. And the price reaction to the news on Day 1 would be less than normal because the price would already have been negatively influenced during the trading hours of Day 1 by the short sales based on the leaked information. Thus, on average, in the second world we would expect to observe that when short sales are above normal, negative news in the overnight hours afterward will have a smaller price reaction the next day.

98. They are not certain because stochastic fluctuations in the levels of the three non-explanatory kinds of short selling, which are unrelated to pre-market news the trading next day, will also influence the day's aggregate level of short selling. 
b. Fundamental-analysis true-news-spreading short selling. To isolate the effect of fundamental-analysis true-news-spreading short selling, suppose that there was no possibility of false-news-spreading short selling or near-announcement inside-information short selling. When participants in the market observe an abnormally high level of short selling during the trading hours of Day 0 and then negative news during the pre-market hours of Day 1, they know that there is an increased chance that some informed trading has already occurred on the basis of the news and so part of its impact on price may already have occurred. Thus, on average, we again would expect to observe that when short sales are above normal on Day 0 , negative news in the overnight hours afterward will have a smaller price reaction on Day 1.

c. False-news-spreading short selling. To isolate the effect of false-news-spreading short selling, suppose that there was no possibility of near-announcement insideinformation short selling or fundamental-analysis true-news-spreading short selling. When market participants observe an unusually high aggregate level of short selling on a given day, they know there is an increased chance that it was due to false-newsspreading short selling. Thus, when market participants observe a high level of short selling during the trading hours of Day 0 followed by negative news during the premarket hours of Day 1, market participants have an elevated fear that this negative news is false. They will discount it somewhat relative to how they would have evaluated the news if they had not observed the high level of short selling. Because of this discounting, the negative news will have less of a price impact when trading occurs on Day 1.

\section{The Efficiency of the Market Responses Under Study}

Our third major finding is that while the joint pattern of above-normal short selling on Day 0 and above-average negativity in news on Day 1 predict belownormal returns on Day 2 and the next trading day thereafter, we find that the predictive content of the negativity does not exhibit a statistically significant dependence on the extent of short selling and vice versa. ${ }^{99}$ Given the power that our tests gain from our large number of observations, this finding suggests that if there is in fact any relationship with the returns on Day 2 and beyond, it is very small.

This third major finding suggests that the market is digesting in an efficient and rational way whatever it knows about the level of short selling on Day 0 that preceded the news on Day 1. The lack of any pattern after the first day suggests that there is no lag in processing the implications of this information and no overreaction on Day

99. The insignificant coefficient on the $($ short_ $O>0) *$ pre_neg_ 1 interaction variable in the second regression in Table 3 represents this finding. This regression employs nearly the same independent variables as the first regression in Table 3, but the dependent variable is now the firm's stock returns in Day 2 (abret_2) instead of its returns on Day 1. Consistent with previous studies, we find that the coefficients on the negativity of news on Day 1 (pre_neg_1 and trad_neg_1) and abnormal short selling on Day 1 (short_1) are negative and statistically significant. Our main focus, however, is on the insignificant coefficient on the interaction term between abnormal short selling on Day 0 and pre-market negativity on Day 1 , which indicates that the stock market's lagged response to negativity does not depend on the extent of short selling that precedes news. See infra Table 3. 
1 that requires subsequent correction. This third major finding suggests as well that the market's high-short-selling-in-Day-0 discount of negative news in the pre-market hours of Day 1 (revealed by our second major finding) is correct on average.

Finally, our third major finding suggests that the market estimates well the extent to which false-news-spreading short selling plays in explaining our first major finding-i.e., that the level of Day 0's short sales of an issuer's shares predicts the negativity of news about the issuer in the pre-market hours of Day 1 . Since the market does not know which news stories are the results of false-news-spreading short selling, it discounts the implications of all stories to reflect this estimate. To the extent that the market figures out within the next nine days which of the negative news stories that it accepted as true on Day 1 are really false, the issuers that are the victims of the false stories enjoy positive returns. There is a counterbalancing negative trend in the returns of the rest of the issuers, where the news was not found not to be false. If the market correctly estimates the role of false-news-spreading short selling, we would expect that when the returns of these two kinds of issuers are averaged, they appear normal. This is what we observe in our third major finding.

\section{CONCLUSION}

This article explores empirically the relationship between short selling and subsequent news about an issuer. We have identified three kinds of short selling that can be connected with such news. One is short sellers who have obtained confidential information that an issuer is about to make a negative announcement. A second is short sellers who, after their sales, spread false stories that generate negative news. The third is short sellers who, through gathering and analyzing publicly available data, have detected that price exceeds fundamental value and, after their sales, spread their true conclusions about this disparity, thereby also generating negative news. Our study exposes a number of key findings that shed new light on the importance of these three news-connected kinds of short selling, both relative to the total amount of short selling in the market and relative to each other.

Our first major finding is that an abnormally high level of short selling during the trading hours of one day tends to be followed by a statistically significant elevation in the level of negative news about an issuer immediately following these sales. According to our analysis, this finding suggests that the three news-connected kinds of short selling are in the aggregate sufficiently important, relative to the total amount of short selling in the market, to generate statistically significant results. The importance of these three news-connected kinds of short selling is reinforced by an additional result from our study - above-average short selling of an issuer's shares on one trading day predicts below-average returns the next trading day, but the ability of the level of short selling to predict returns is greater when there is news concerning an issuer in the pre-market hours of this next trading day. Another result from our study - that when the level of short selling is below normal, there is no positive relationship between the level of short selling one trading day and the level of negative news the next-hints at the relative importance of news-spreading short 
selling (both false and true) versus short selling based on inside information concerning an upcoming issuer announcement, because this is the pattern that we would particularly expect news-spreading short selling to display.

Our second major finding is that when an issuer is the subject of negative news in the pre-market hours of a trading day, the price reaction to the news during the trading hours that follow is less pronounced where there has been an abnormally high level of short selling the day before. This finding is yet another indicator of the significance of news-connected short selling relative to the total level of short selling.

Our third major finding is that the ability of negative news that follows short selling to predict returns beyond the next trading day after the short selling does not depend on the level of this short selling. This suggests that the market is digesting in an efficient and rational way whatever it knows about the level of short selling that precedes negative news.

In sum, while prior empirical studies have suggested that short sales based on confidential information that an issuer is about to make a negative earnings surprise announcement are significant relative to the total amount of short selling occurring immediately in advance of such announcements, the preliminary results of our study expand the horizon in two ways. First, they relate to all kinds of news about an issuer, not just issuer announcements of negative earnings surprises. Second, the explanation of our results relates to all three kinds of news-connected short selling, not just short selling based on confidential information from inside an issuer. We have substantial evidence that these three kinds of short selling in the aggregate are significant relative to the total amount of short selling occurring in advance of negative news. We have further evidence that at least hints that news spreading, whether false or true, represents a significant portion of all news-connected short selling.

While our results are not yet sufficiently specific to suggest refinements of regulatory policy, they do establish that important things are going on that relate short selling to news. They are thus a spur to further research that could guide policy. We have evidence relating to both the importance of news-connected short selling in general and news-spreading short selling in particular. We currently do not have evidence concerning the relative roles of false-news-spreading short selling, which is unambiguously socially harmful, versus true-news-spreading short selling, which results in socially beneficial improvements in share price accuracy. Thus, the regulatory implications of our work depend in part on whether further study will reveal the relative proportions of true-news-spreading short selling versus false-newsspreading short selling and whether it will permit the development of empirical indicators of the situations where false-news-spreading short selling is most likely to have occurred. ${ }^{100}$

100. Even if we or others were able to find that false-news-spreading short selling is a significant phenomenon on its own, this finding would not, in our view, make a persuasive case for wholesale restrictions on short selling. Such a finding would of course reinforce the concern from theory that the availability of short selling increases the prevalence of the fraudulent practice of spreading false news and trading to take advantage of the resulting distortion in price by making the practice more convenient to undertake. See supra Part I.C.4. But, as the overall discussion in Part I demonstrates, this effect is just one piece in 
As an additional extension, we want to investigate the negative relation between short selling and news during below-average short selling days. We do not have a clear explanation here of this result but it is possible that on days in which insiders or news spreaders are buying in great volume, traders who effectively act as market makers are shorting. Also, our study has so far focused exclusively on the extent to which short sales forecast future news. The alternative direction-news forecasting short sales-is also of interest. Some traders might, for example, seek to profit by spreading false positive news and then selling short at the resulting increased price with the knowledge that the price rise will likely be only temporary. If this occurs on a regular basis, then good news should on average forecast increased short sales. We look forward to further exploring the numerous ways in which short selling and news may be related.

a complicated story of social benefits and harms that arise from the availability of short selling. See supra Part I. We suspect that in general the benefits of short selling well outweigh the other harms discussed earlier, and therefore a finding that false-news-spreading short selling is a significant phenomenon is unlikely to tip the balance.

On the other hand, such a finding, in a telltale way, would spot a light on the more general practice of spreading false news and trading to take advantage of the resulting price distortion, and show that the practice may be more serious than previously believed. This would suggest that it be the object of more serious enforcement efforts. 


\section{TABLE 1: THE ABILITY OF SHORT SELLING TO PREDICT NEWS NEGATIVITY}

This table reports the coefficients and standard errors from two linear regressions of news negativity on Day 1 (pre_neg_1) on abnormal short selling activity on Day 0 (short_0). We measure short selling in the 9:30 a.m. to 4:00 p.m. interval on Day 0 and news negativity (in percentages) in the 4:00 p.m. to 9:30 a.m. interval on Day 1 that follows. The two regressions depicted in columns two and three represent two different subsamples. The first column contains all observations, whereas the second column contains only observations in which short selling is above normal on Day 0 (i.e., short_O is positive). Key control variables include percentage news negativity in the pre-market and trading hours in Day 0 (pre_neg_O and trad_neg_O), the firm's market-adjusted stock returns (abret_O), its abnormal trading volume (volm_O), and its market capitalization (size_o). See the text for further details. The standard errors of the regression coefficients in parentheses adjust for correlations among different firms' stock returns in the same day. The * and ** marks indicate statistical significance at the $5 \%$ and $1 \%$ levels, respectively.

\begin{tabular}{|l|c|c|c|}
\hline Independent Variables & $\begin{array}{c}\text { All } \\
\text { Observations }\end{array}$ & $($ short $0>0)$ & $($ short_0 $\leq 0)$ \\
\hline short_0 & 0.042 & $0.179^{* *}$ & $-0.150^{* *}$ \\
\hline & $(0.022)$ & $(0.041)$ & $(0.053)$ \\
\hline pre_neg_0 & $0.206^{* *}$ & $0.203^{* *}$ & $0.208^{* *}$ \\
\hline & $(0.005)$ & $(0.007)$ & $(0.006)$ \\
\hline trad_neg_0 & $0.208^{* *}$ & $0.216^{* *}$ & $0.202^{* *}$ \\
\hline & $(0.007)$ & $(0.009)$ & $(0.008)$ \\
\hline abret_0 & $-0.865^{* *}$ & $-0.798^{* *}$ & $-0.906^{* *}$ \\
\hline & $(0.082)$ & $(0.129)$ & $(0.100)$ \\
\hline volm_0 & $0.033^{* *}$ & $0.032^{* *}$ & $0.032^{* *}$ \\
\hline & $(0.003)$ & $(0.005)$ & $(0.004)$ \\
\hline size_0 & $0.012^{* *}$ & $0.016^{* *}$ & $0.011^{* *}$ \\
\hline & $(0.001)$ & $(0.002)$ & $(0.002)$ \\
\hline$R^{2}$ & $5.71 \%$ & $5.77 \%$ & $5.68 \%$ \\
\hline Independent Trading & 1,282 & 1,281 & 1,282 \\
Days & & & 169,834 \\
\hline Observations & 307,382 & 137,548 & \\
\hline
\end{tabular}




\section{TABLE 2: THE ABILITY OF SHORT SALES TO PREDICT STOCK RETURNS ON NEWS DAYS}

This table reports the results from two regressions predicting a firm's marketadjusted return on Day 1 (abret_1 in percentages) using abnormal short selling activity on Day 0 (short_O) and other variables. Both regressions include an interaction term between abnormal short selling activity on Day 0 and the presence of premarket news on Day 1 (short_O ${ }^{*}$ pre_news_O). The two columns present two regression specifications: one with the main coefficients of interest and the other that includes several additional control variables. Control variables include a pre-market news measure (pre_news_O) equal to one when there is at least one story about the firm and zero when there are no such stories; a story measure (pre_story_o) equal to the square root of the number of newswire messages about a firm; a word measure (pre_words_0) equal to the square root of the number of words per newswire; and the pre-market news negativity measure (pre_neg_o in percentages). See the text and Table 1 for descriptions of the other variables. The standard errors of the regression coefficients in parentheses adjust for correlations among different firms' stock returns in the same day. The * and ${ }^{* *}$ marks indicate statistical significance at the $5 \%$ and $1 \%$ levels, respectively.

\begin{tabular}{|l|c|c|}
\hline Independent Variables & Baseline Specification & $\begin{array}{c}\text { All Controls } \\
\text { Included }\end{array}$ \\
\hline short_0 & $-0.165^{* *}$ & $-0.167^{* *}$ \\
\hline & $(0.015)$ & $(0.015)$ \\
\hline short_0*pre_neww_0 & $-0.215^{* *}$ & $-0.235^{* *}$ \\
\hline & $(0.068)$ & $(0.065)$ \\
\hline pre_neww_0 & 0.017 & 0.026 \\
\hline pre_neg_0 & $(0.010)$ & $(0.023)$ \\
\hline & & $-0.155^{* *}$ \\
\hline pre_story_0 & & $(0.009)$ \\
\hline & & -0.005 \\
\hline pre_words_0 & & $(0.022)$ \\
\hline & & $0.003^{* *}$ \\
\hline$R^{2}$ & $0.01 \%$ & $(0.001)$ \\
\hline Independent Trading Days & 1,295 & $0.11 \%$ \\
\hline Observations & $2,881,691$ & 1,295 \\
\hline
\end{tabular}




\section{TABLE 3: THE COMBINED ABILITY OF SHORT SALES AND NEGATIVITY TO PREDICT RETURNS}

This table displays the results from linear regressions of a firm's market-adjusted stock returns on Day 1 or Day 2 (abret_1 or abret_2) on the interaction between abnormal short selling on Day 0 and news negativity on Day $1(($ short_o 0 ) * pre neg_1 or (short_O $>0) *$ trad_neg_1). The regression includes control variables for short selling activity on Days 0 and 1 (short_0 or short_1) and news negativity in the pre-market and trading hours of Day 0 (pre_neg_1 or trad_neg_1), in addition to the market capitalization, trading volume, and news variables described earlier. See the text and Tables 1 and 2 for descriptions of the other variables. The standard errors of the regression coefficients in parentheses adjust for correlations among different firms' stock returns in the same day. The * and ${ }^{* *}$ marks indicate statistical significance at the $5 \%$ and $1 \%$ levels, respectively.

\begin{tabular}{|l|c|c|}
\hline Independent Variables & Dependent Var: abret_1 & $\begin{array}{c}\text { Dependent } \\
\text { Var: abret_2 }\end{array}$ \\
\hline short_1 & & $-0.243^{* *}$ \\
\hline & & $(0.047)$ \\
\hline short_0 & $-0.320^{* *}$ & 0.052 \\
\hline & $(0.054)$ & $(0.043)$ \\
\hline pre_neg_1 & $-0.137^{* *}$ & $-0.028^{* *}$ \\
\hline$\left(\right.$ short_0>0) ${ }^{*}$ pre_neg_1 & $(0.009)$ & $(0.006)$ \\
\hline & $0.025^{*}$ & 0.008 \\
\hline trad_neg_1 & $(0.011)$ & $(0.009)$ \\
\hline & $-0.173^{* *}$ & $-0.024^{* *}$ \\
\hline$\left(\right.$ short_0>0) ${ }^{*}$ trad_neg_1 & $(0.012)$ & $(0.007)$ \\
\hline & $0.043^{* *}$ & 0.002 \\
\hline$R^{2}$ & $(0.015)$ & $(0.009)$ \\
\hline Independent Trading Days & $0.35 \%$ & $0.19 \%$ \\
\hline Observations & 1,295 & 1,284 \\
\hline
\end{tabular}

